\title{
1 NUMERICAL MODELLING OF THE IVENS SHAFT CONSTRUCTION IN
}

\section{LISBON}

3

4

5

6

7

8

9

António Pedro, ISISE, Department of Civil Engineering, University of Coimbra, Portugal

Lidija Zdravković, Department of Civil and Environmental Engineering, Imperial College London, UK

David Potts, Department of Civil and Environmental Engineering, Imperial College London, UK

Jorge Almeida e Sousa, Department of Civil Engineering, University of Coimbra, Portugal

\section{ABSTRACT}

The traditional use of shafts is that of simple geotechnical structures, built to provide direct access to the subsoil to either access existing facilities, or to provide a launch chamber for new excavations. More recently, shafts have been constructed with complex geometries and directly incorporated as part of a permanent basement or metro station. One such complex structure is the Ivens shaft in Lisbon, Portugal, which is yet to be built. The construction of this shaft represents a geotechnical challenge due to its complex shape and location in central Lisbon, surrounded by several historic buildings and having in its close vicinity the Baixa-Chiado metro station. This paper presents a sophisticated 3D numerical simulation of the Ivens shaft construction, with a focus on assessing its effect on the existing buildings and the metro station and on the structural forces induced in its lining. The importance of integrating in the analysis the appropriate constitutive modelling of the different formations, the realistic initialisation of the ground conditions and the stiffness of the buildings, is discussed in detail. Although this is a class A prediction of a specific case study, it provides an insight into the general soil-structure interaction of a complex underground excavation. 


\section{INTRODUCTION}

The increasing use of underground space in metropolitan areas has led to an increase in shaft construction, since they provide the most direct access route to the subsoil (McNamara et al., 2008; Schwamb \& Soga, 2015). The term shaft is typically employed to define a geotechnical structure which has a depth larger than its width (Muramatsu \& Abe, 1996) and that connects the ground surface to the underground. They are typically vertical, as this minimises the length and the overall cost of the excavation (Holl \& Fairon, 1973). Historically, the typical shape of the shaft in the horizontal plane has changed from being rectangular to circular due to the development of new construction techniques (Holl \& Fairon, 1973) and because a circular section is more structurally efficient, requiring a much thinner lining (Muramatsu \& Abe, 1996).

Over the last twenty years the development of underground railway networks in the cities of Lisbon and Oporto has led to the construction of several shafts in Portugal. Initially these shafts were built with the principal purpose of launching new tunnel excavation fronts, or in order to create access points to existing tunnels and stations. They were mainly circular in plan and were excavated after the installation of vertical diaphragm or secant pile walls. The challenges involved with the numerical modelling of circular shafts using diaphragm walls have been discussed in the literature, accounting for their construction in different ground conditions (Goto et al., 1994; Kumagai et al., 1999; Anagnostopoulos \& Georgiadis, 2002; Cabarkapa et al., 2003; Zdravkovic et al., 2005; Arai et al., 2008; Schwamb \& Soga, 2015). Subsequently, shafts with an elliptical shape in plan were introduced in order to maximise the space for the underground station platforms and to minimise the amount of excavated material from the shaft (Andrade et al., 2004; Topa Gomes et al., 2008). However, increased space constraints led the designers to more audacious and radical solutions such as those adopted in the Salgueiros station (Topa Gomes, 2008) and in the Reboleira station of the Oporto and Lisbon metros, respectively, where several elliptical shafts were connected by large concrete frames, as shown in Figure 1. Given the local ground conditions, the expensive and time consuming conventional 
construction method, which involves the construction of support walls followed by excavation, was replaced by the vertical construction sequence methodology. This latter approach follows similar principles as those defined for the NATM (Rabcewicz, 1964) for tunnelling. In that methodology the excavation is usually performed sequentially, either in small benches or as a full fixed-depth cycle, depending on the shaft dimensions and soil properties. Shotcrete, sometimes combined with other support components, is then applied to the exposed ground surface before the excavation of a new bench/cycle begins.

Despite its increasing use, this type of complex solution and construction methodology (Andrade et al., 2004; Morrison et al., 2004; Campanhã \& Kuwajima, 2008; Vincenza et al., 2012) has not been studied in detail (França et al., 2006; Topa Gomes et al., 2008; Tavares et al., 2010). Consequently, its interaction with the soil remains, to a certain degree, unknown. The importance of an in depth investigation is highlighted by the widely reported accident in January 2007, involving the Pinheiros station of the São Paulo metro in Brazil (Barros et al., 2008; IPT, 2008). Here the collapse of a connection tunnel propagated back to the Capri shaft, part of which failed causing several fatalities and irreparable damage to several adjacent buildings.

The objective of this paper is to investigate the behaviour of this type of shaft construction and contribute towards a better understanding of the induced soil-shaft interaction with the surrounding buildings and services. For this purpose, the case study of the future Ivens shaft in Lisbon is analysed in detail using advanced three-dimensional (3D) numerical analysis. Consequently, in many respects the presented results form class A predictions, according to Lambe (1973), i.e. before the construction in the field takes place. The numerical study presented here builds on carefully performed site investigation and characterisation of the ground conditions, reported by the authors in Pedro et al. $(2017,2018)$. 

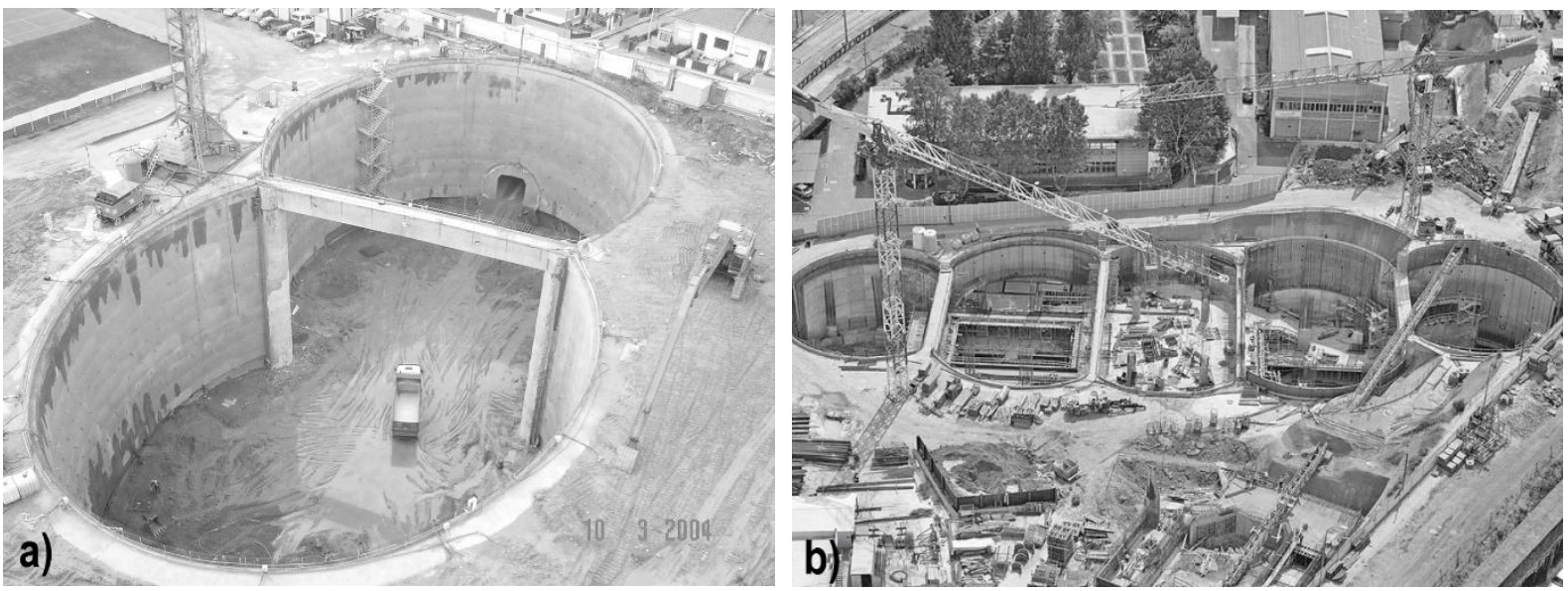

Figure 1 - Examples of shafts excavated at Portugal: a) Salgueiros station - Oporto Metro (2004); b) Reboleira station - Lisbon Metro (2010)

\section{IVENS SHAFT}

The purpose of the Ivens shaft is to provide an additional access route to the Baixa-Chiado metro station of the Lisbon Metro network (Postiglione et al., 1997) which opened in 1998. Although construction of the Ivens shaft was included in the original project brief for the metro station, this has been successively delayed, mainly due to financial constraints. The principal function of the shaft is to provide direct and rapid access to the station (Cenorgeo, 2008). The relative positions of the BaixaChiado station and Ivens shaft are shown in Figure 2. The shaft is located in the backyard of the Quintão building, with access via Ivens street, and is surrounded by several historic buildings.

The geometry of the shaft is complex mainly due to restrictions at the ground surface and can be divided into 4 different zones, as shown in Figures 3 and 4. The top zone involves the construction of $5 \mathrm{~m}$ deep retaining walls which form a rectangular retaining structure $17 \mathrm{~m}$ by $10 \mathrm{~m}$ in plan. This is required to support the $6 \mathrm{~m}$ of backyard fill material adjacent to the shaft when this material is removed from within the shaft, reducing the ground surface here to the street level (Figure 5). The second zone, $19 \mathrm{~m}$ deep, has an elliptical section in plan with major and minor axes of $12.2 \mathrm{~m}$ and $8.3 \mathrm{~m}$, respectively. This is followed by a transition zone were the geometry changes from an elliptical to circular form over a depth of $9.7 \mathrm{~m}$. The last section of the shaft is circular in plan, with a $14.9 \mathrm{~m}$ diameter and $7.8 \mathrm{~m}$ depth. 
The retaining structure at the ground surface will be constructed from $40 \mathrm{~cm}$ thick concrete walls installed before excavation begins. The rest of the shaft excavation will be performed in steps, $1 \mathrm{~m}$ deep, and divided horizontally into 4 benches in order to minimise its impact on the surrounding buildings and services. The initial support applied during the benched excavation will consist of fibre reinforced shotcrete. After the completion of full excavation an impermeable membrane and a secondary concrete lining will be installed. Due to the soil stresses increasing with depth, the thickness of the shotcrete increases from $30 \mathrm{~cm}$ in the elliptical section, to $45 \mathrm{~cm}$ in the transition zone and to $60 \mathrm{~cm}$ in the circular section (Figure 4). Columns of jet-grouting, $1 \mathrm{~m}$ in diameter, will be placed around the perimeter of the transition zone prior to its excavation, as shown in Figure 4, in order to improve safety during the stage of section enlargement and also to ensure that the excavation is performed in dry conditions, as at this location there is a seam of coarser soil with a relatively high permeability (Figure 5).

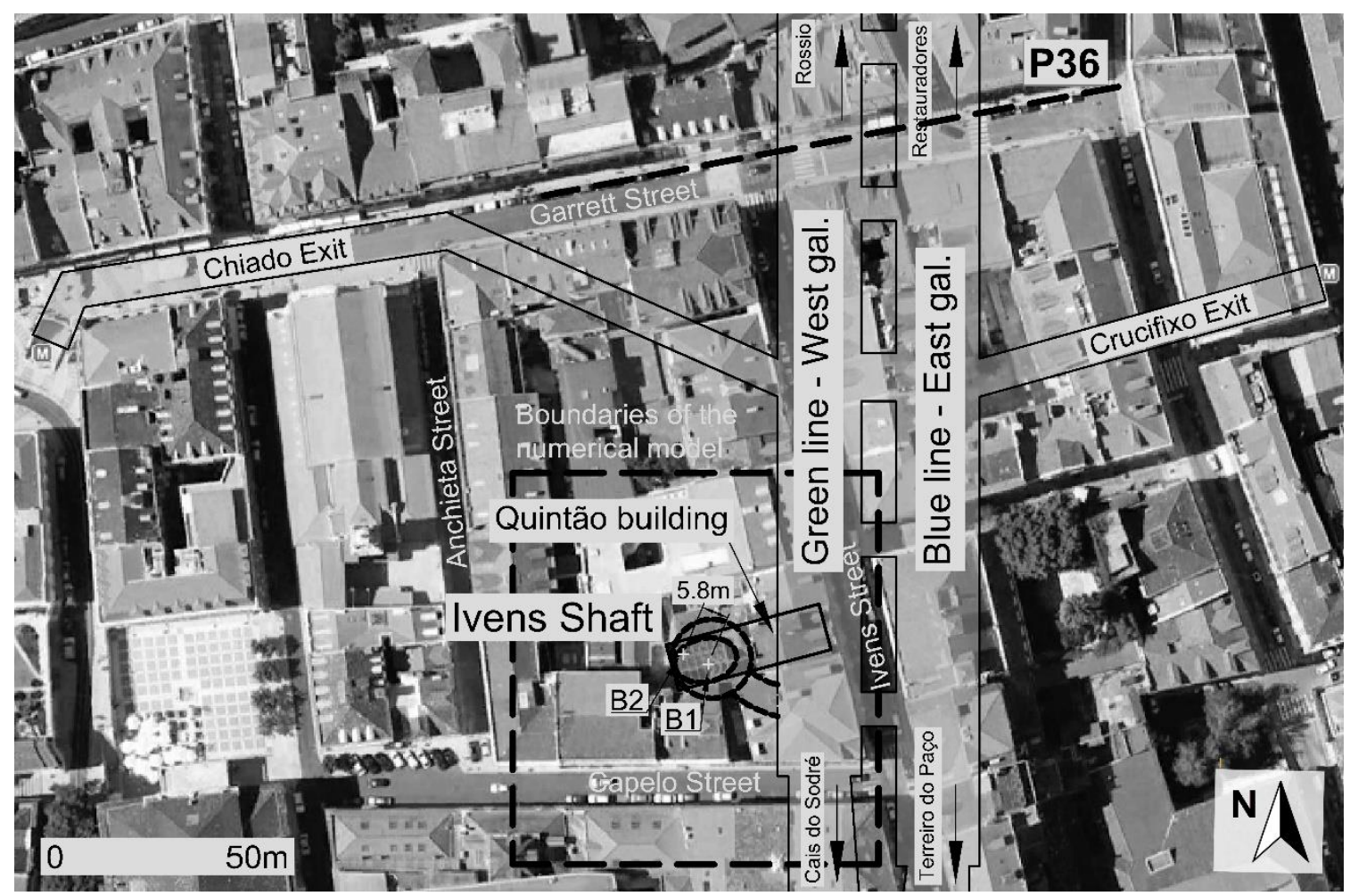

Figure 2 - Location and insertion of the Baixa-Chiado station in Lisbon downtown (modified from Google Earth) 

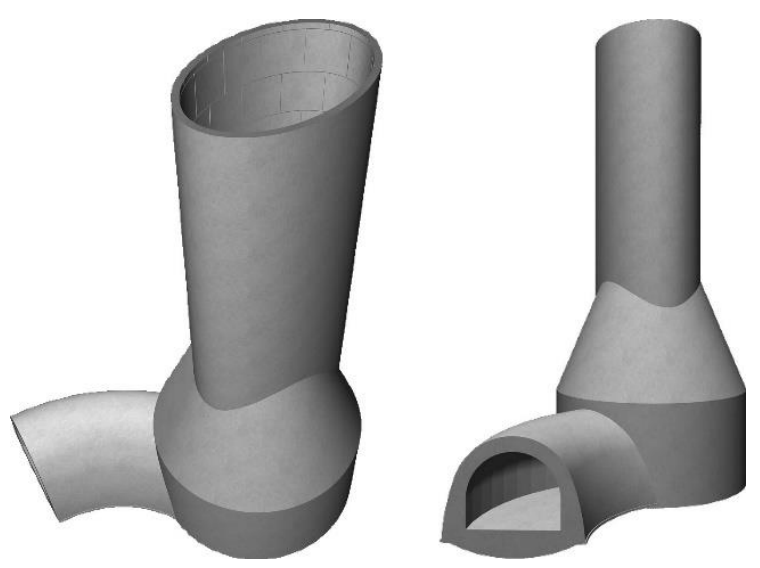

Figure 3-3D perspectives of the Ivens shaft (Cenorgeo, 2008)
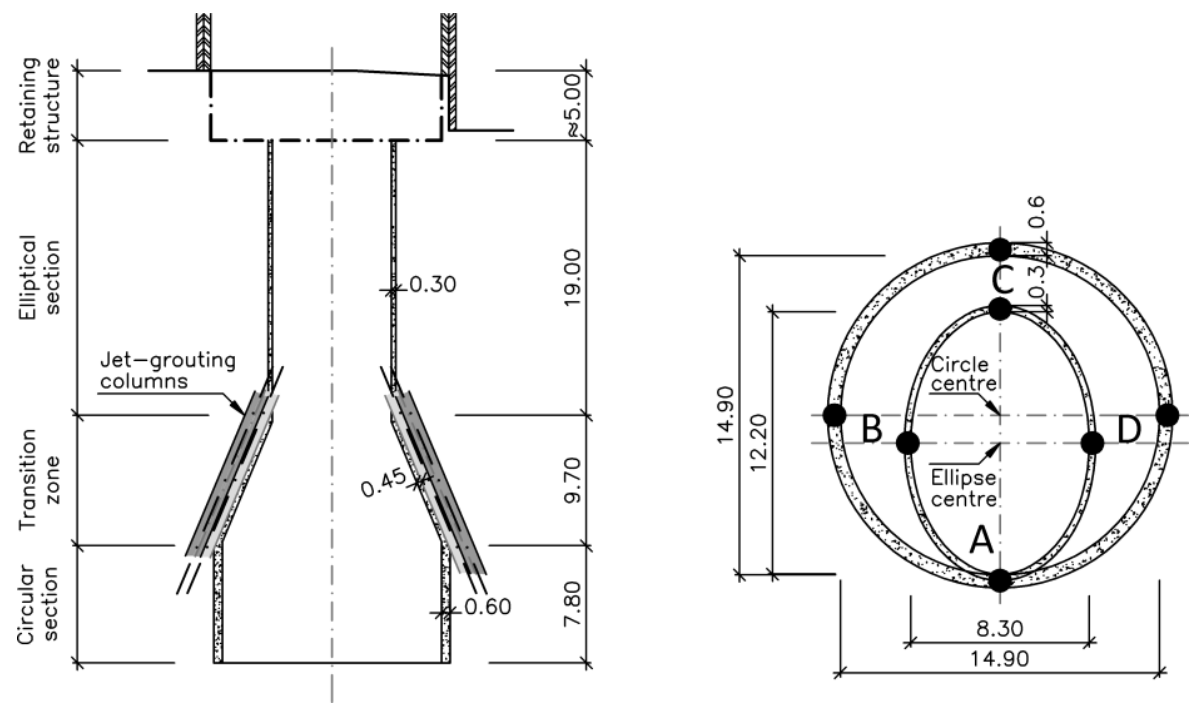

Figure 4 - Dimensions and geometry of the Ivens shaft (modified from Cenorgeo, 2008)

\section{GEOTECHNICAL PROFILE AT THE IVENS SHAFT SITE}

The initial characterisation of the Ivens shaft site relied on ground investigations conducted in 1994 for the design of the Baixa-Chiado station (Postiglione et al., 1997), and subsequently in 1997 for the Ivens shaft design (Cenorgeo, 2008). However, to enable the derivation of soil parameters for advanced numerical analysis, an additional ground investigation was conducted in 2010 (Pedro, 2013), involving both in-situ and laboratory experiments on the soils in the Ivens ground profile, utilising two new boreholes drilled to a depth of about $40 \mathrm{~m}$, measured from street level, and marked as B1 and B2 in Figure 2. A full characterisation of the ground profile, with a synergy of the historic and the new data, is presented in Pedro et al. (2018) and Pedro (2013). 
The ground profile is shown in Figure 5 , consisting of a $6 \mathrm{~m}$ thick loose sandy fill, underlain by the sandy

"Areolas da Estefânia" (AE) formation which extends to 31m depth (measured from street level), followed by the clayey "Argilas e Calcários dos Prazeres" (AP) formation. The material between 31m and $33 \mathrm{~m}$ depth is a transition between the $A E$ and $A P$ layers, having a different degree of cementation, and was hence characterised as a different unit (TAP) (Pedro et al., 2018). At depths between $8 \mathrm{~m}$ and $13 \mathrm{~m}$ the $A E$ formation is bisected by a thick layer of fossiliferous and highly jointed limestone $(L)$. As illustrated in Figure 5 , the soil layers are inclined at less than $5^{\circ}$ towards the city centre, i.e. in the southeast direction. However, as this is a small gradient and there are uncertainties in the transition zones between layers due to material heterogeneity, the geological model for the shaft analysis considered these as horizontal. The water table was found at $23 \mathrm{~m}$ depth, $8 \mathrm{~m}$ above the TAP formation, and the soil above it was found to be saturated, apart from the coarser zones below the Limestone layer as described by Pedro et al. (2018).

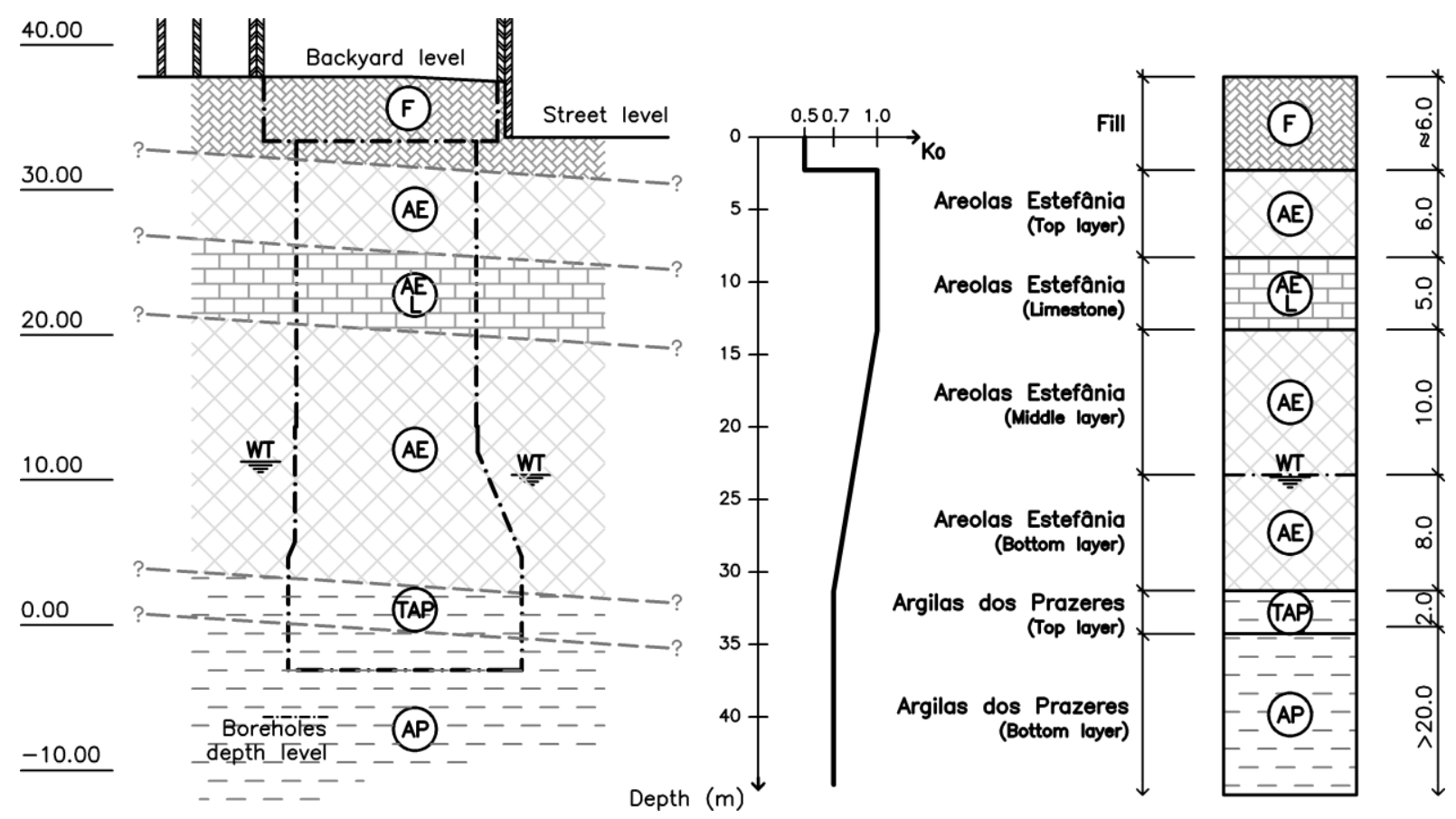




\section{NUMERICAL MODEL}

135

136

137

138

139

140

141

142

143

144

145

146

147

148

149

150

151

152

153

154

155

156

\subsection{FINITE ELEMENT MESH AND BOUNDARY CONDITIONS}

The analyses were performed using the finite element (FE) code ICFEP (Potts \& Zdravković, 1999; Potts \& Zdravković, 2001). The complex geometry of the shaft and its construction sequence, the presence of the Baixa-Chiado station, connection tunnel and the historic buildings adjacent to the shaft required a full 3D FE model, albeit with some simplifications to reduce the computational cost.

The developed model is $80 \mathrm{~m}$ by $80 \mathrm{~m}$ in plan, with model boundaries marked by the dashed black line in Figure 2. The shaft is located at the centre of the model, while a plane of symmetry is assumed along the central axis between the West and East galleries of the Baixa Chiado station. Due to the complexity of the model, and to reduce the computational domain, only the West tunnel (closer to the shaft) is discretised in the FE mesh. This implies that the West and East galleries are constructed simultaneously in the model. Figure 6 shows the complete FE model, with the stratigraphy assumed to consist of horizontal layers identified in Figure 5, thus neglecting their marginal inclination. The base of the model is located at $51 \mathrm{~m}$ depth. The view on the FE model in Figure 6 is from the north side, therefore showing the West gallery of the Baixa-Chiado station, immediately to the right of the plane of symmetry, and the outline of the elliptical shape of the shaft in the corner of building types marked as 6 and 7 . The West gallery has an approximate diameter of $17.5 \mathrm{~m}$ and the distance from street level to the crown is on average $28 \mathrm{~m}$.

All materials in the model domain (soil, buildings, shaft and tunnel linings, jet grout columns) are discretised with 20-noded hexahedral elements (Figure 6). Details of all infrastructure components hidden inside the mesh are shown in Figure 7, with their thicknesses reproduced as indicated in Figure 4. Since the fibre-reinforced shotcrete support is applied directly against the soil, no interface elements are introduced between the soil and structural elements and therefore full bonding is assumed. 
Throughout the analysis no horizontal movements are allowed normal to the vertical boundaries of

158 the model domain and no movements, in any coordinate direction, are permitted at the base of the

159 model. Due to the presence of water in the ground, a coupled hydro-mechanical analysis is performed.

The soil below the ground water table is considered to undergo hydro-mechanical coupling and consequently the relevant finite elements have pore water pressure degrees of freedom at their corner nodes in addition to displacement degrees of freedom. The finite elements representing the soil above the ground water table and the structural components simulate only the mechanical behaviour and consequently have only displacement degrees of freedom. Throughout the analysis a zero pore water pressure is imposed at the ground water table and no change in pore water pressure (from the initial hydrostatic distribution below the water table) is imposed on the nodes of the West (see Figure 6) vertical boundary of the model which have pore pressure degrees of freedom, ensuring that water could flow in or out of the model. A zero flow condition (an impermeable boundary) is imposed on the remaining three vertical sides (these being planes of symmetry) and the base of the model. From the stage of the analysis when the shaft excavation reaches the ground water level onwards, a zero pore water pressure condition is imposed on the exposed surfaces of the shaft (bottom and lateral sides) and connecting tunnel excavations to simulate drained conditions. This boundary condition implies that water could flow from the shaft into the soil if suctions are generated in the soil. However, in the analysis small suctions are generated only at the end of excavation in a small zone immediately below the shaft's base. As the base slab is constructed during the next stage of analysis, insufficient time is available for any significant flow of water from the shaft into the soil. It was therefore deemed reasonable to retain a zero pore water pressure on the exposed shaft surface below the ground water level. Once constructed, all linings are assumed to be impermeable, to reflect the installation of a membrane around the entire surface of the excavation. 


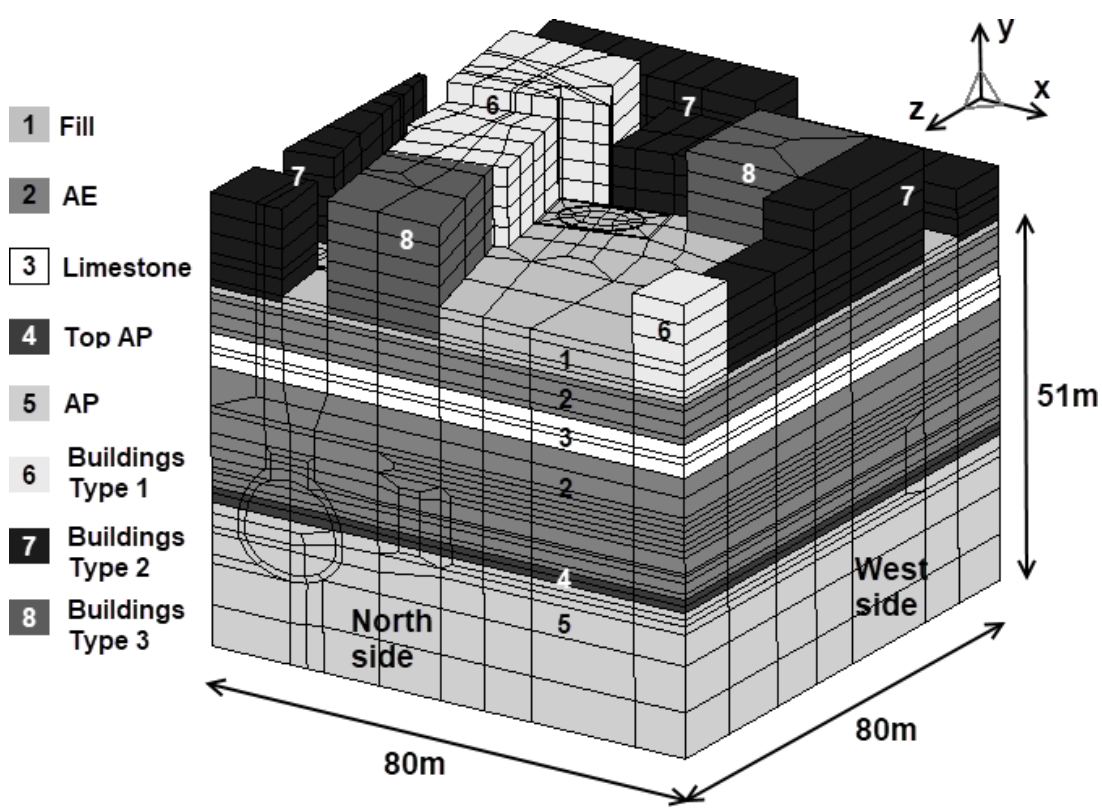

Figure 6 - Finite element mesh and geotechnical ground profile in the 3D FE model

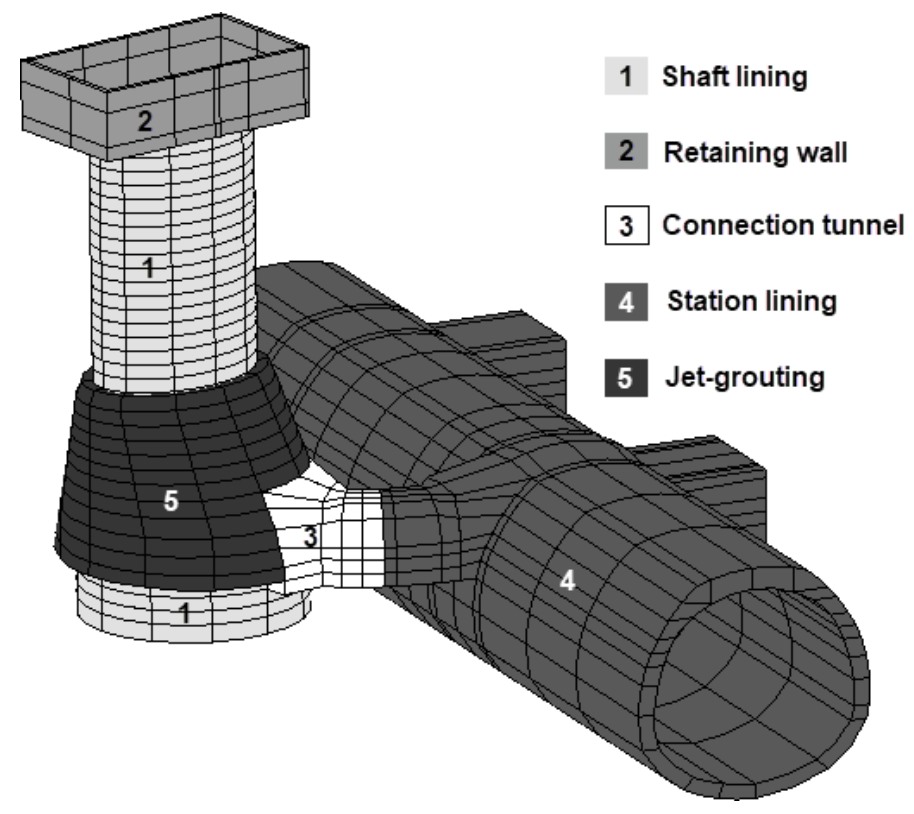

Figure 7 - Infrastructure components in the 3D FE model

\subsection{CONSTITUTIVE MODELLING}

Based on the interpretation of ground conditions by Pedro et al. (2018), the choice of appropriate constitutive models and their calibration were presented and discussed in Pedro et al. (2017). The same reference also shows a validation of the adopted constitutive modelling, employing a 2D finite element analysis in the case study of the Baixa-Chiado station construction which benefited from the field monitoring of ground movements during construction (both West and East galleries). The very 
good agreement between numerical predictions and field measurements is the basis for adopting the same constitutive modelling and model parameters in the 3D FE analysis of the Ivens shaft construction in the current paper. Only a brief summary of the selected constitutive models and model parameters is given here.

The fill is modelled as a linear elastic-perfectly plastic material using a non-associated Mohr-Coulomb (MC) model. A nonlinear non-associated Mohr-Coulomb (NMC) model (see Appendix) is selected to define the plastic behaviour of the AE formation (a sandy layer of a varying degree of cementation), while its stiffness is modelled with the Imperial College Generalised Small Strain Stiffness (IC.G3S) model (Taborda et al., 2016; see Appendix). The Limestone layer is also modelled as a linear elasticperfectly plastic material, but with the NMC model. Finally, for both the TAP and AP formations, the stiffness is simulated by the IC.G3S model, while the plasticity is controlled by a conventional nonassociated MC model. This is a low plasticity clay (PI of about 20\%), with its top layer (TAP) being softer due to the influence of the AE layer above. The small strain stiffness model for each soil describes both the shear and bulk stiffness variations. For each of the soil layers below the ground water table a constant value of permeability is assumed. The model parameters for all soils, derived by Pedro et al. (2018), are summarised in Table 1.

Six different structural materials are simulated using solid elements. An isotropic linear elastic model is adopted for the retaining walls and the linings of the station tunnel, shaft and connecting tunnel. Different stiffness values are considered for shotcrete linings depending on their age. The behaviour of the jet grout is based on the results of laboratory tests presented by Candeias et al. (2007). A linear elastic-perfectly plastic model, with the plasticity defined by a non-associated Mohr-Coulomb model, is adopted. The parameters assumed for the structural materials are presented in Table 2. 


\begin{tabular}{|c|c|c|c|c|c|c|c|}
\hline \multirow{2}{*}{ Designation } & \multirow{2}{*}{ Material } & \multirow{2}{*}{ Model } & \multicolumn{3}{|c|}{ Yielding properties } & \multicolumn{2}{|c|}{ Elastic parameters } \\
\hline & & & $c^{\prime}(\mathrm{kPa})$ & $\phi^{\prime}(\mathrm{o})$ & $\psi(\mathbf{0})$ & $\mathrm{E}(\mathrm{GPa})$ & $v$ \\
\hline Shaft lining & Shotcrete & Linear elastic & - & - & - & 8.0 & 0.25 \\
\hline Retaining wall & Concrete & Linear elastic & - & - & - & 20.0 & 0.25 \\
\hline Bottom /Top slabs & Concrete & Linear elastic & - & - & - & 20.0 & 0.25 \\
\hline Connection tunnel & Shotcrete & Linear elastic & - & - & - & 8.0 & 0.25 \\
\hline Station lining & Concrete & Linear elastic & - & - & - & 23.0 & 0.25 \\
\hline Jet-Grouting & Grouting & Mohr-Coulomb & 700 & 40 & 0 & 0.8 & 0.20 \\
\hline
\end{tabular}

217 Fourteen buildings are fully or partially simulated as equivalent blocks by continuum (3D) elements in the 3D model. Based on a characterisation survey the buildings are placed into three groups according to the manner of their construction and current condition. The oldest buildings have mainly a brickwork or masonry load-bearing wall structure, with most of the floors constructed with pine or oak timber. For those that are in the poorest condition (type 1 in Figure 6) a slab stiffness (E) of 7.5GPa is adopted while a value of $12 \mathrm{GPa}$ is assumed for the remaining buildings of this type (type 2 in Figure 6 ). In both cases the thickness of the equivalent timber slabs is assumed to be $20 \mathrm{~cm}$. The more recent buildings have a reinforced concrete frame structure and hence a Young's modulus of 23GPa and a slab thickness of $15 \mathrm{~cm}$ are conservatively assumed. In all cases a Poisson's ratio of 0.25 is assumed. Based on these values and on the dimensions of the buildings, equivalent stiffness parameter (E) values of 500, 850 and $1150 \mathrm{MPa}$ are derived for building types 1, 2 and 3 (Figure 6) respectively, following the methodology presented by Franzius (2003) and Franzius et al. (2006) (see Appendix).

\subsection{CONSTRUCTION SEQUENCE}

The construction sequence adopted in the analysis simulates the construction stages defined in the design project of the Ivens shaft, as summarised in Table 3, together with the appropriate elapsed times. Ground conditions prior to shaft construction are established first. Ideally this should involve

233 the simulation of all the processes that have occurred at the site since the deposition of the soil layers.

234 As most of these processes are not known in detail a simplification is applied. Firstly, an initial stress 235 field is generated assuming greenfield conditions. Then the construction of the buildings and the Baixa- 

construction of the Ivens shaft.

Table 3 - Stages modelled in the analyses

\begin{tabular}{|c|c|c|c|c|}
\hline Increment & Stage & Description & $\begin{array}{l}\text { Time (years) } \\
\text { Per increment }\end{array}$ & $\begin{array}{l}\text { Accumulated } \\
\text { time (years) }\end{array}$ \\
\hline $0-0$ & \multirow{4}{*}{$\begin{array}{l}\text { Initial } \\
\text { conditions }\end{array}$} & $\begin{array}{l}\text { Greenfield conditions: initial stresses based on bulk unit weight, } \\
\mathrm{K}_{0} \text { value and hydrostatic pore water pressures }\end{array}$ & 0 & 0 \\
\hline $1-35$ & & Construction of the buildings & 0.0857 & 3.00 \\
\hline & & Construction of the Baixa-Chiado station & & \\
\hline $36-50$ & & $\begin{array}{l}\text { Consolidation to simulate elapsed time since the construction of } \\
\text { the buildings and of the Baixa-Chiado station }\end{array}$ & 1.2000 & 21.00 \\
\hline $51-54$ & \multirow{5}{*}{$\begin{array}{l}\text { Construction } \\
\text { of the shaft }\end{array}$} & $\begin{array}{l}\text { Construction of the retaining wall and excavation of the soil } \\
\text { inside }\end{array}$ & 0.0046 & 21.02 \\
\hline $55-162$ & & $\begin{array}{l}\text { Excavation of the soil and shotcrete support of the elliptical zone } \\
\text { of the shaft }\end{array}$ & 0.0046 & 21.52 \\
\hline $162-162$ & & Construction of the jet grouting columns & 0.0000 & 21.52 \\
\hline $163-216$ & & Excavation and support of the transition zone of the shaft & 0.0046 & 21.76 \\
\hline $217-258$ & & $\begin{array}{l}\text { Excavation and support of the circular zone of the shaft and } \\
\text { construction of the bottom slab }\end{array}$ & 0.0046 & 21.96 \\
\hline $259-267$ & $\begin{array}{l}\text { Connection } \\
\text { tunnel }\end{array}$ & Excavation and support of the connection tunnel & 0.0046 & 22.00 \\
\hline
\end{tabular}

241 Construction of the shaft starts with the construction of the $40 \mathrm{~cm}$ thick perimeter walls, simulated by continues until the bottom of the shaft is reached, regardless of the cross sectional shape of the shaft.

247 After completing the elliptical section at a depth of $20 \mathrm{~m}$, excavation is paused to simulate installation 248 of the jet-grout columns. This stage is simulated by changing the material properties of the finite elements forming the columns, from soil to jet grout. The excavation and lining of the transition and circular zones are then completed and the $60 \mathrm{~cm}$ thick bottom slab is constructed. 

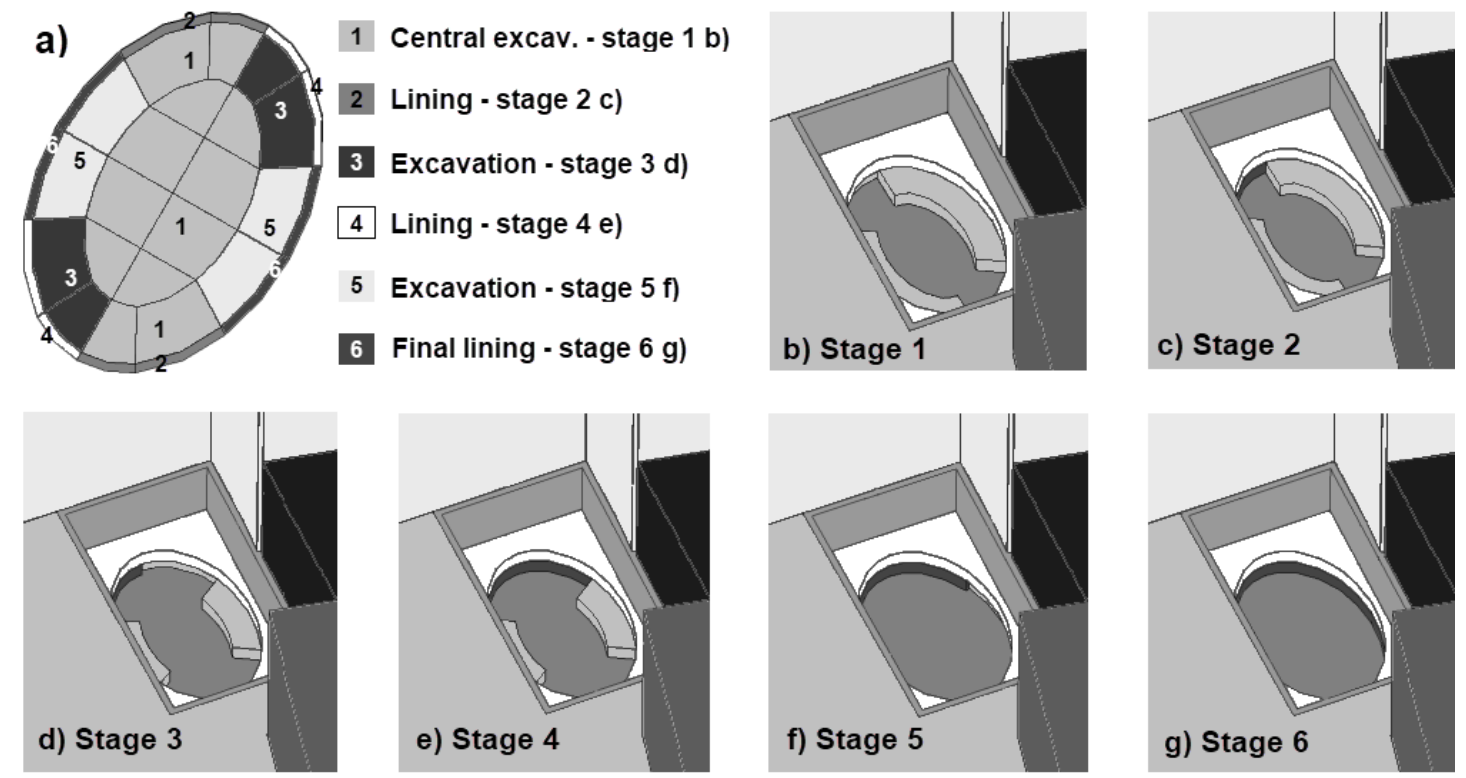

Figure 8 - Details of the excavation of each $1 \mathrm{~m}$ deep step of the Ivens shaft: a) excavation and construction scheme in plan; b) stage 1 ; c) stage 2 ; d) stage 3 ; e) stage 4 ; f) stage 5 ; g) stage 6)

\section{MODELLING THE INITIAL GROUND CONDITIONS}

As noted above, this stage of the analysis involves the simulation of processes from greenfield conditions up to the start of shaft construction (the first 50 increments, as summarised in Table 3).

Consequently, the analysis starts by establishing the greenfield initial stresses in the ground, with the vertical effective stress calculated from the bulk unit weights of the soils, given in Table 1, and the pore water pressure which is assumed hydrostatic below the ground water level and zero above it. The horizontal effective stress is calculated from the $K_{0}$ profile interpreted from field experiments by Pedro et al. (2018) and shown in Figure 5. assuming a $10 \mathrm{kPa}$ surcharge load per each floor. The average magnitude of the boundary stress applied over the footprint of the buildings is $40 \mathrm{kPa}$, the maximum being 60 and the minimum $10 \mathrm{kPa}$. 
The excavation of the West gallery of the Baixa-Chiado station is simulated with a slightly modified

271 sequence, involving only a top heading and a bench, for simplicity. The actual excavation involved more

272 stages in both the West and East galleries (top heading, side drifts and multiple benches), which were all simulated in the 2D FE validation analysis reported in Pedro et al. (2017). Furthermore, the plane of symmetry along the axis between the two galleries in the current 3D FE analysis implies that these are excavated simultaneously, whereas the process was sequential in the 2D analysis and in the field (West gallery first). Consequently, to ensure that a realistic stress relief in the ground is achieved in the current 3D analysis, the tunnel excavation is simulated using the stress relief method (Panet \& Guenot, 1982). To establish the appropriate magnitude of the stress relief factor, the resulting ground surface settlement trough from the 3D analysis is calibrated against the measured (at alignment P36 in Figure 2) and predicted (from the $2 D$ analysis of Pedro et al. (2017)) ground surface settlement troughs. This results in a stress relief factor of 0.5 , for which a comparison of the three settlement troughs is shown in Figure 9. Because of the assumed symmetry plane between the two galleries in the 3D FE model, only the results of the left half of the settlement trough are obtained. The very good agreement between them implies that the simplifications of tunnel construction applied in the 3D analysis are unlikely to introduce significant errors. Other than the modification of the excavation stages, the construction of the West gallery in the 3D analysis adopts the same hydraulic boundary conditions as the $2 \mathrm{D}$ analysis, with a zero pore water pressure imposed at the tunnel perimeter surface prior to lining installation, while this boundary becomes impermeable after the construction of the $1 \mathrm{~m}$ thick lining. station. 


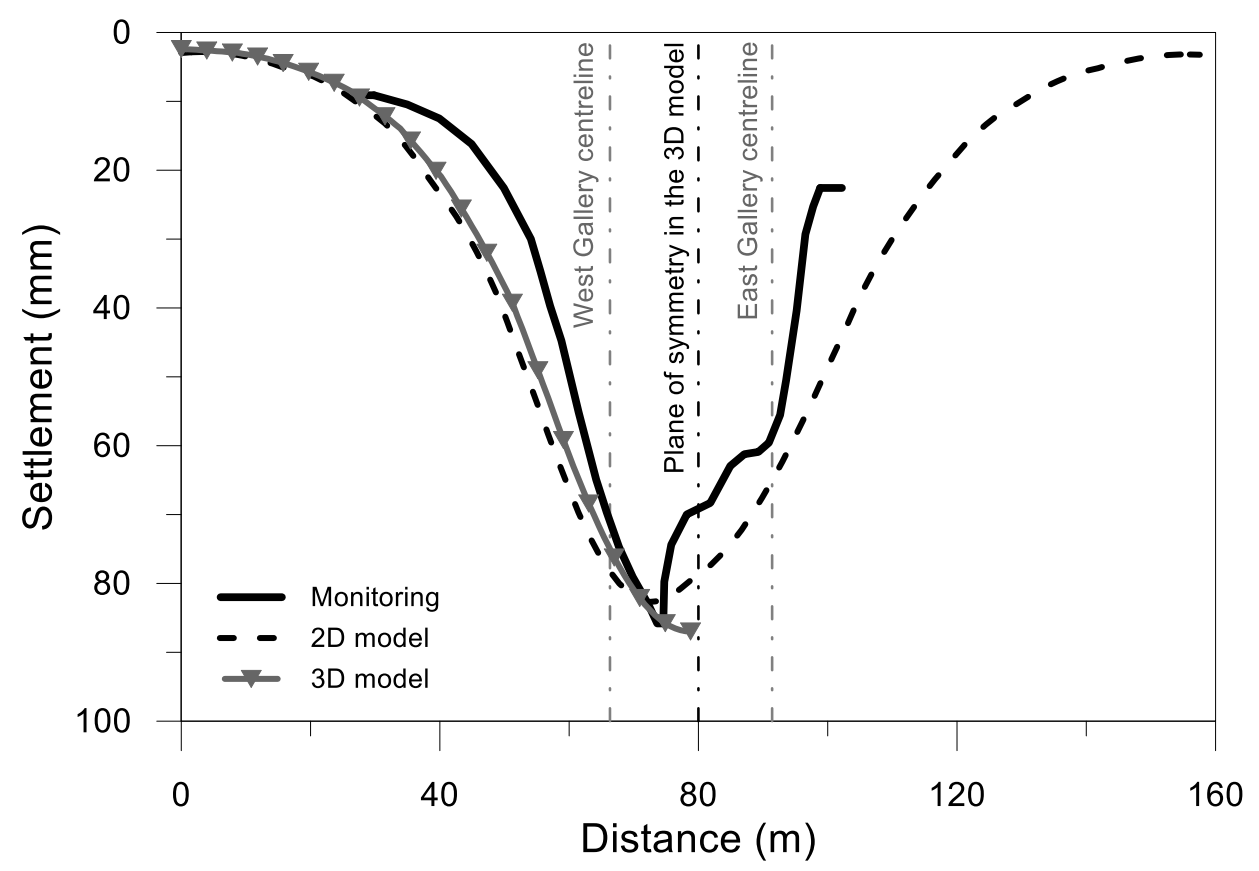

Figure 9 - Comparison of the settlement troughs for the Baixa-Chiado station

The 18 years of excess pore pressure dissipation, subsequent to the construction of the buildings and the Baixa-Chiado station, bring the ground conditions to the current state (increment 50), just before the start of shaft excavation. Significant stress changes have occurred in the ground with respect to the initial greenfield conditions assumed at the start of the analysis, as shown in the example of the mean effective stress, $p^{\prime}$, contours in Figure 10. In particular, a considerable increase of $p^{\prime}$ is observed in the central pillar between the two galleries, due to the increase in the vertical stress as a result of arching caused by tunnel excavation. It is also noted that all excess pore water pressures dissipated during this period of consolidation.

a)

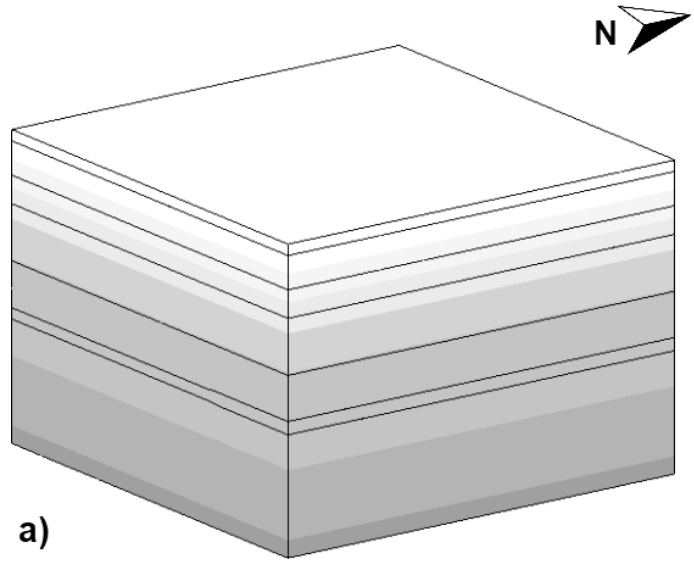

Figure 10 - Contours of mean effective stress: a) greenfield; b) prior to shaft construction 


\section{CONSTRUCTION OF THE IVENS SHAFT}

304

305

306

307

308

309

310

311

312

313

314

315

316

317

318

319

320

321

322

In the following sections the results of the 3D FE analysis for the construction of the Ivens shaft are presented and discussed in detail. In order to isolate the effects of the shaft construction all displacements arising from the set up of the initial ground conditions are subtracted from displacements accumulated at subsequent stages of the analysis. Results from two analyses are presented and compared, one (C-A) in which the stiffness of the buildings is set to zero and the other (C-B) in which the equivalent stiffness of the buildings is modelled, as described above.

\subsection{GROUND DEFORMATIONS CAUSED BY THE EXCAVATION}

\section{Surface deformations}

Contours of the vertical displacements at the ground surface after completion of shaft construction are plotted in Figure 11. The plan view outlines the footprint of the buildings, the backyard and the streets around the Ivens shaft. The surface settlement troughs along the major and minor axes of the shaft at the level corresponding to the depth of the building foundations, i.e. $1 \mathrm{~m}$ below the street level, are shown in Figure 12. The influence of the buildings' stiffness is clearly seen when comparing the results from the two analyses in both figures. The contours in the C-A analysis are concentric around the excavation in Figure 11, while they are restrained in the C-B analysis due to the stiffness of the buildings. This is consistent with field measurements and numerical predictions in other wellreported studies (e.g. Jubilee Line Extension tunnels in London clay (Standing et al., 1998; Potts \& Zdravković, 2001; Viggiani \& Standing, 2001)). The magnitude of the settlement is larger in the C-A analysis, particularly around the shaft, where a maximum difference of $40 \%$ is observed along the major axis on the side of the station, and below the foundations of the adjacent buildings. The maximum settlements occur in the backyard near the retaining wall and reach values of approximately $25 \mathrm{~mm}$. However, these are localised in a small area of the fill and tend to decrease rapidly with distance away from the wall. The settlements immediately adjacent to the shaft do not exceed $20 \mathrm{~mm}$. Apart from a very small range of non-zero ground surface settlements at the northern boundary in the 
C-B analysis (Figure 11), the extent of the ground affected by the excavation is within the modelled domain at all depths and consequently any boundary effects should be minimal. Comparison of the results from the two analyses highlights the importance of the buildings in restraining the magnitude and distribution of the settlements. The shape of the settlement trough is also modified, with higher differential movements being predicted when the building restrictions are not present (Figure 12).
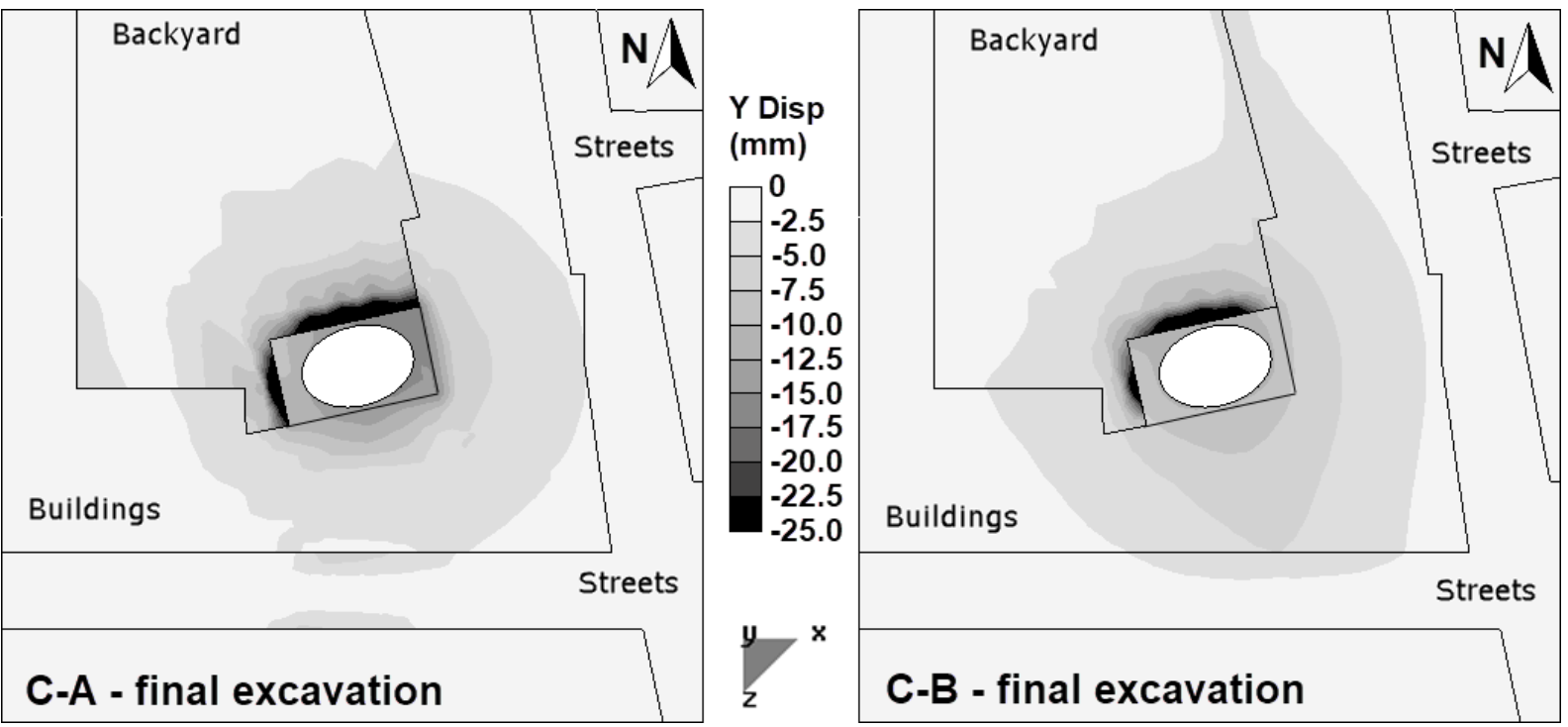

Figure 11 - Vertical deformation (Y Disp) at ground surface after shaft construction (settlements -ve)
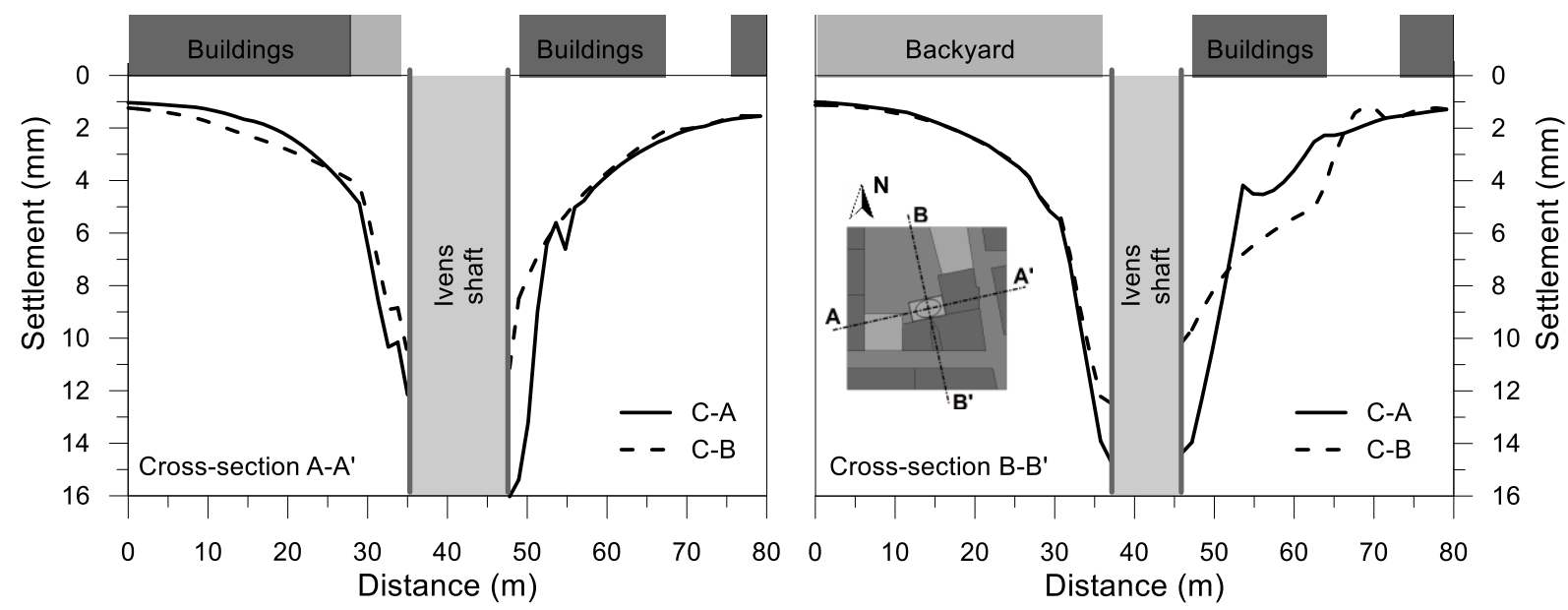

Figure 12 - Settlement profiles at the foundation level of the buildings

Contours of horizontal movements at foundation level of the buildings in both the $\mathrm{X}$ and $\mathrm{Z}$ directions

for this stage of the analyses are presented in Figure 13 and Figure 14 respectively. They indicate 
movements. In this analysis the horizontal displacements converge towards the excavation almost

symmetrically in relation to the shaft axes. In the C-B analysis a different pattern is observed, with the

342 horizontal movements being restrained by the presence of the buildings (almost zero beneath them),

343 reinforcing the conclusion that their stiffness has a significant role in controlling deformations.

344 Nevertheless, the magnitudes of the horizontal displacements predicted by both analyses are relatively

345 small, with maximum values of approximately 3 and $5 \mathrm{~mm}$ in the $\mathrm{X}$ and $\mathrm{Z}$ directions respectively.
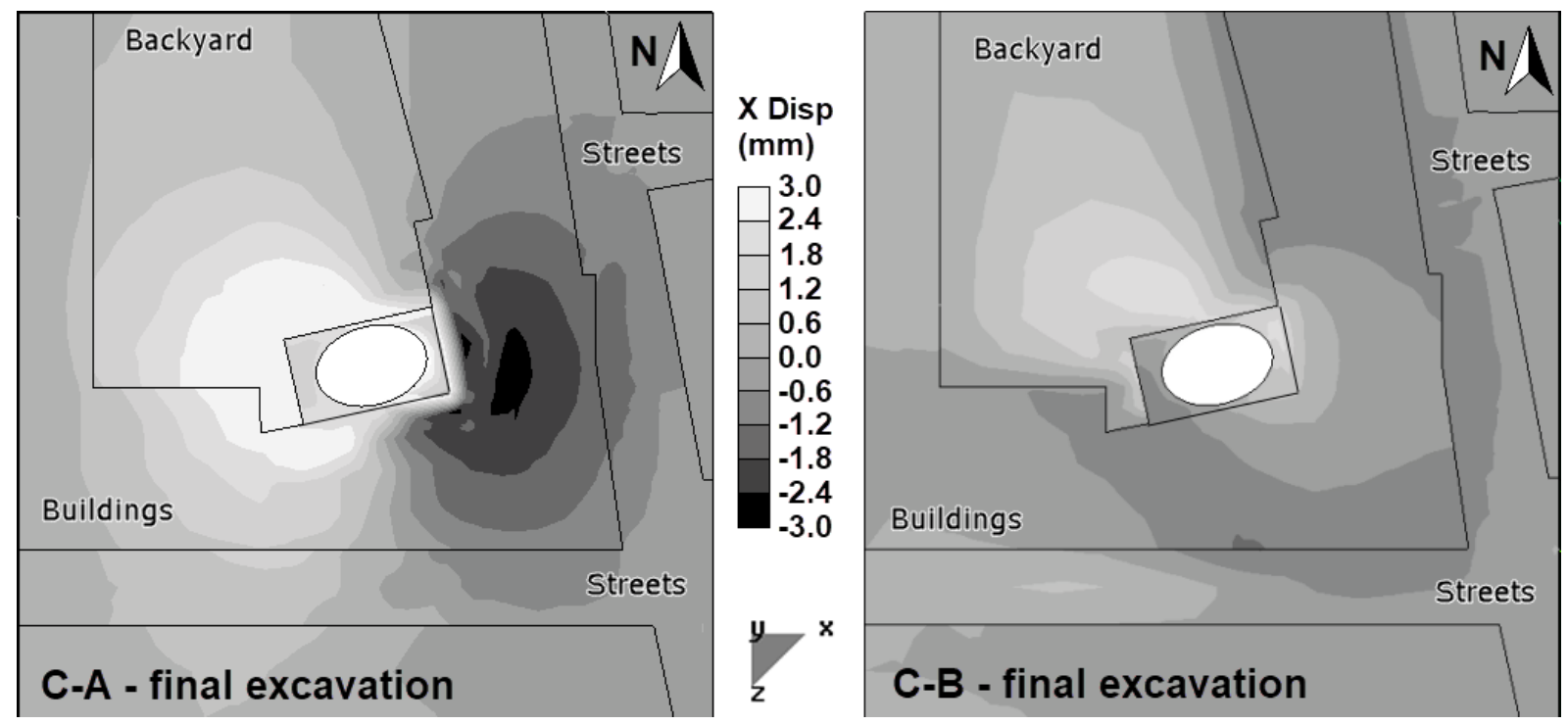

Figure 13 - Horizontal deformation (X Disp) at foundation level of the buildings after shaft construction
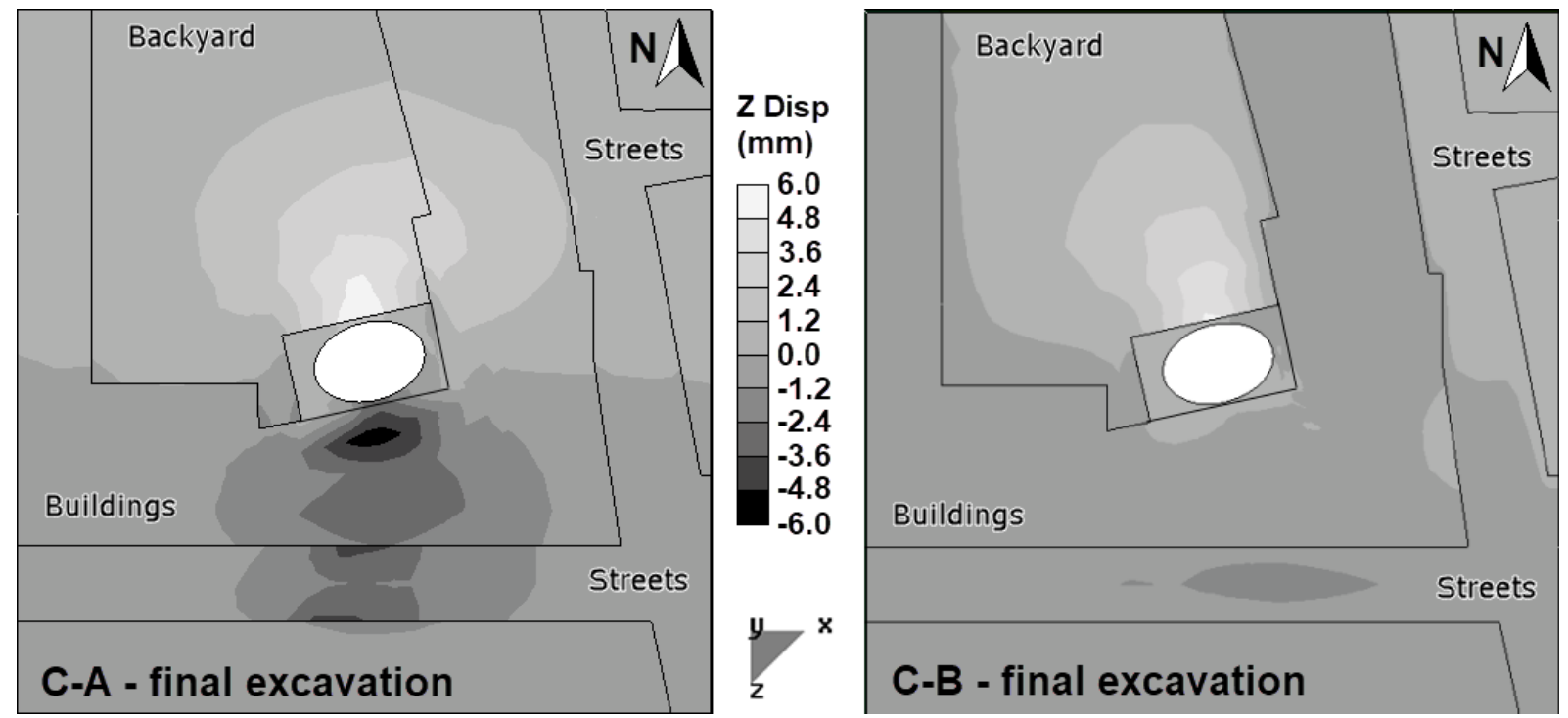

Figure 14 - Horizontal deformation (Z Disp) foundation level of the buildings after shaft construction 
To illustrate the sub surface behaviour, contours of the vertical displacements after completing the shaft construction, for a vertical cross section through the major shaft axis ( $A-A^{\prime}$ in Figure 12), are presented in Figure 15. The settlements are concentrated adjacent to the shaft and in particular at the transition zone and are up to $40 \%$ higher in the C-A analysis, with the difference between the two analyses being particularly noticeable at ground surface on the side of the station. The hatched area below the bottom of the shaft represents a zone in which heave occurs and contours are not displayed for the benefit of visualisation. However, maximum heave occurs below the centre of the shaft base with a magnitude of $20 \mathrm{~mm}$.
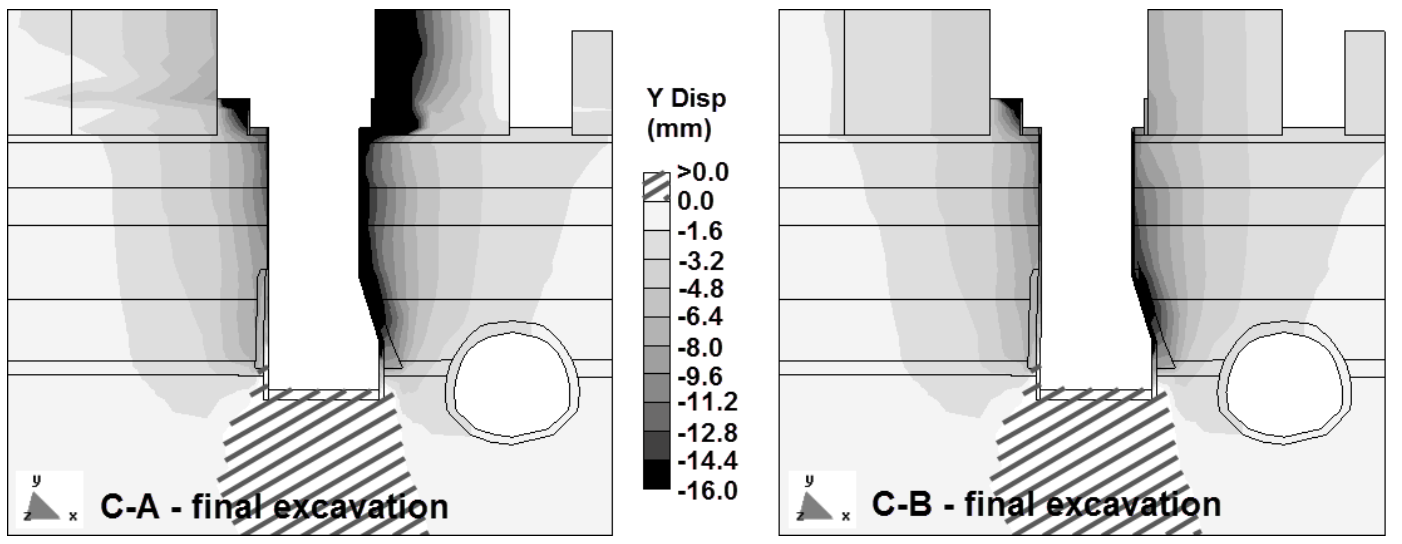

Figure 15 - Contours of vertical displacements in cross-section A-A' after shaft construction (settlements -ve)

\subsection{BEHAVIOUR OF THE SHAFT}

\section{Lining displacements}

The evolution of vertical displacements with the progression of shaft excavation for the 4 vertices of the shaft ( $A, B, C$ and $D$ defined in Figure 4$)$ and from both analyses, is shown in Figure 16 for their location at two depths, $1 \mathrm{~m}$ (black lines) and $25 \mathrm{~m}$ (grey lines). The results reveal that at all 4 points there is approximately a linear relationship between the increase in settlement and the increase in excavation depth. The movements at both locations stabilise after completion of the shaft, with only small increases occurring during the construction of the connection tunnel. Analysis C-A predicts larger displacements throughout the shaft construction, with the differences particularly significant for profiles from $1 \mathrm{~m}$ depth, reaching nearly $40 \%$ at point $\mathrm{C}$. The patterns of displacements also differ, as 
point $C$, located on the side of the station, is predicted to settle the most, while point $A$, the furthest

372 from the station, moves the least, in analysis C-A. In contrast, analysis C-B predicts smaller movements

373 at points $A, D$ and $C$, as these are affected by the vicinity of the buildings, while point $B$ settles the most as it faces the backyard. These results highlight again the importance of the building stiffness in controlling the magnitude and even the pattern of settlements with depth. These differences become negligible at the points located at $25 \mathrm{~m}$ depth were both analyses predict similar settlements. The effect of the shallow-founded buildings seems to have ceased, with point A settling the least in both analyses as its vertical profile remains constant with depth, experiencing a smaller effect of the enlargement in the transition zone compared to the other three points.

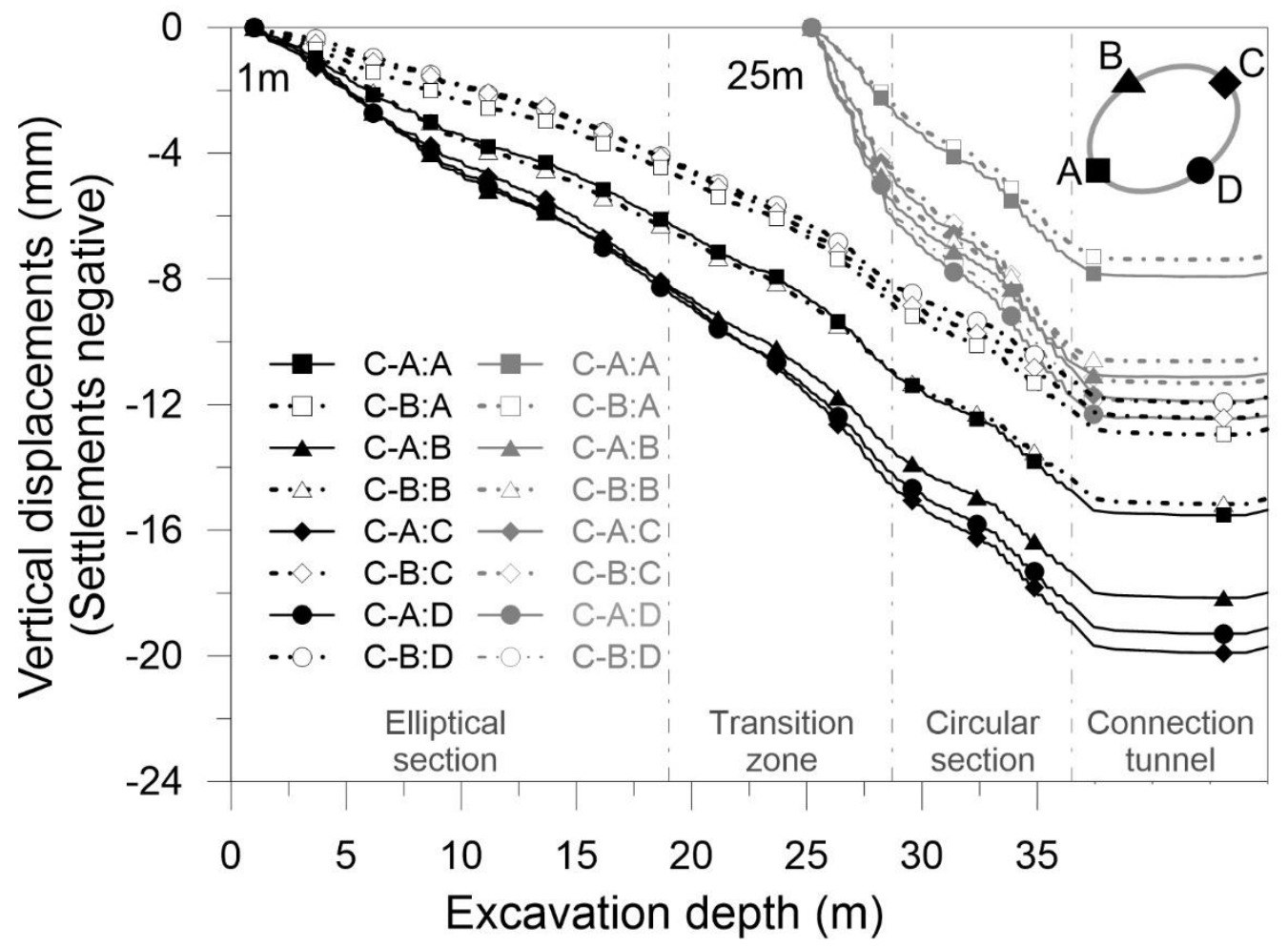
Figure 16 - Vertical displacements of points located on the shaft at 1 and $25 \mathrm{~m}$ depths (settlements -ve)

The evolution of horizontal convergences with the progression of shaft excavation, across the major (grey lines) and minor (black lines) axes of the shaft, is shown in Figure 17 at 4 depths $(1,11,19$ and $25 \mathrm{~m})$. The first observation from this figure is that of significantly different patterns developing across the two axes. The major axis is hardly changing, experiencing in both analyses up to a millimetre divergence to $19 \mathrm{~m}$ depth, and only up to $2 \mathrm{~mm}$ convergence at $25 \mathrm{~m}$ depth. Only convergence is 
predicted across the minor axis from both analyses, the maximum being about $12 \mathrm{~mm}$ at $19 \mathrm{~m}$ depth, which coincides with the end of the elliptical section and start of the enlargement. It is also evident that both analyses predict nearly the same magnitudes of convergence or divergence across both axes for sections at $11 \mathrm{~m}$ depth and deeper, which indicates that the effect of the surface buildings has ceased at this depth of excavation. However, their effect is clearly evident for the cross-section at $1 \mathrm{~m}$ depth, with smaller convergence and divergence across the minor and major axes, respectively, predicted from the C-B analysis.

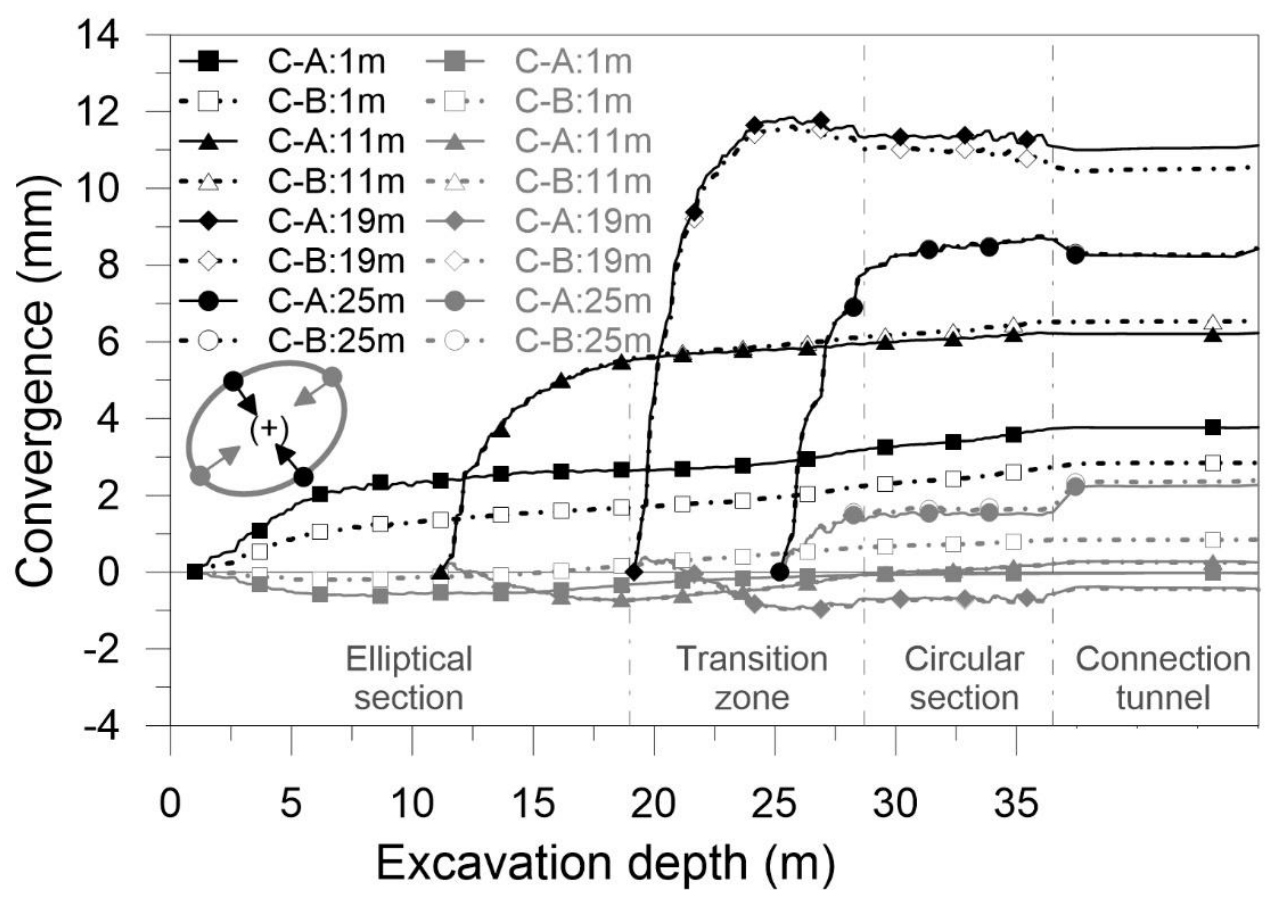

Figure 17 - Horizontal convergence of the principal axes of the shaft at different depths

\section{Forces and pressures acting in the lining}

The circumferential hoop forces (always in compression) in the shaft lining at different horizontal cross sections, after completion of shaft construction, are presented in Figure 18. Differences between the two analyses only occur in the shallow part of the shaft (section at $5 \mathrm{~m}$ depth), implying that the building stiffness does not affect the behaviour at depth. Near the surface the circumferential hoop force is almost constant across the lining, while at a depth it varies, having its maximum around point C. 
404 around the lining for several horizontal cross sections are shown in Figure 19. The figure shows only

405 small differences between the two analyses at all depths, implying little influence of the building

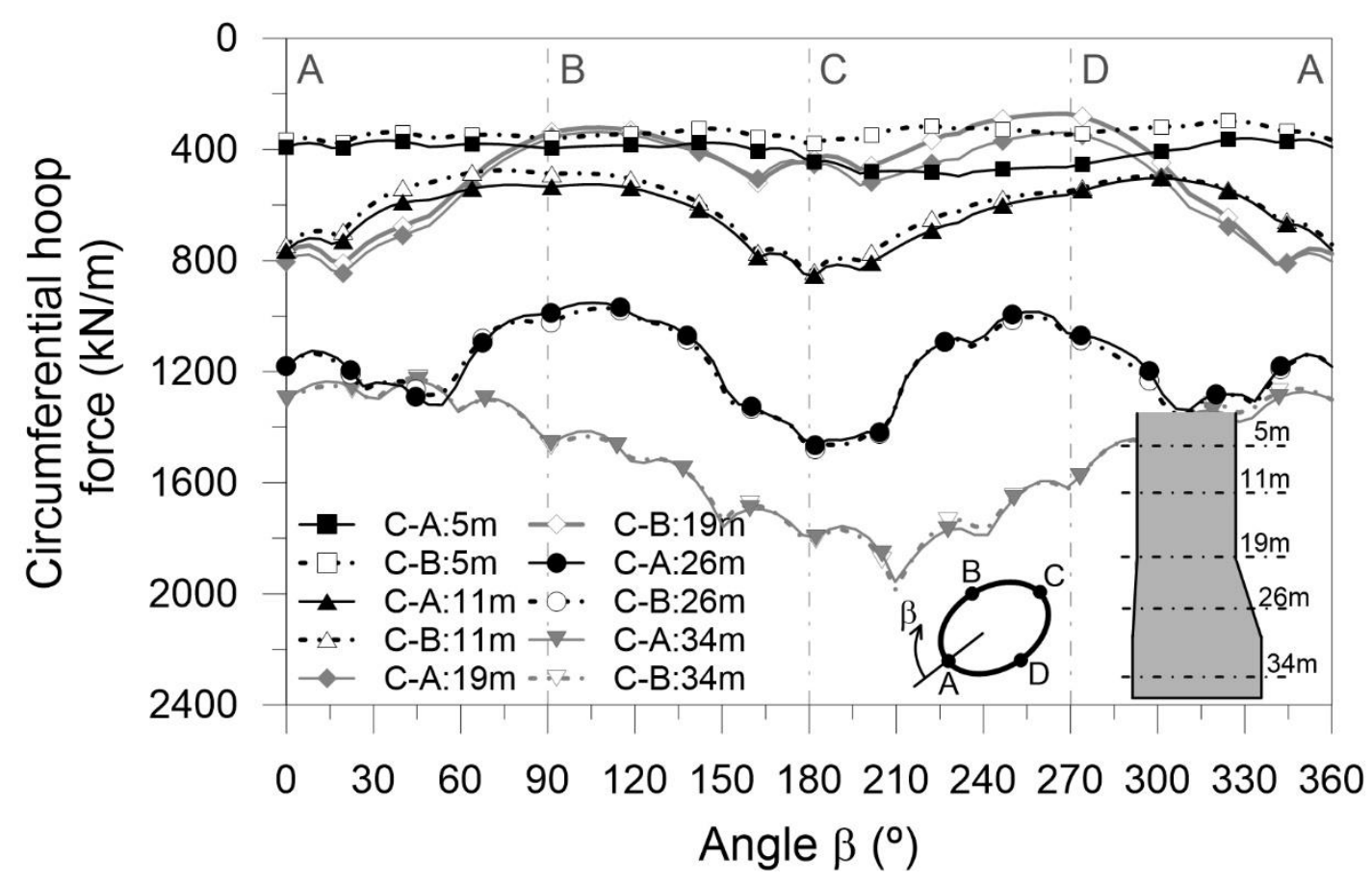

408

Figure 18 - Circumferential hoop force mobilised in the lining of the shaft for the final stage of excavation

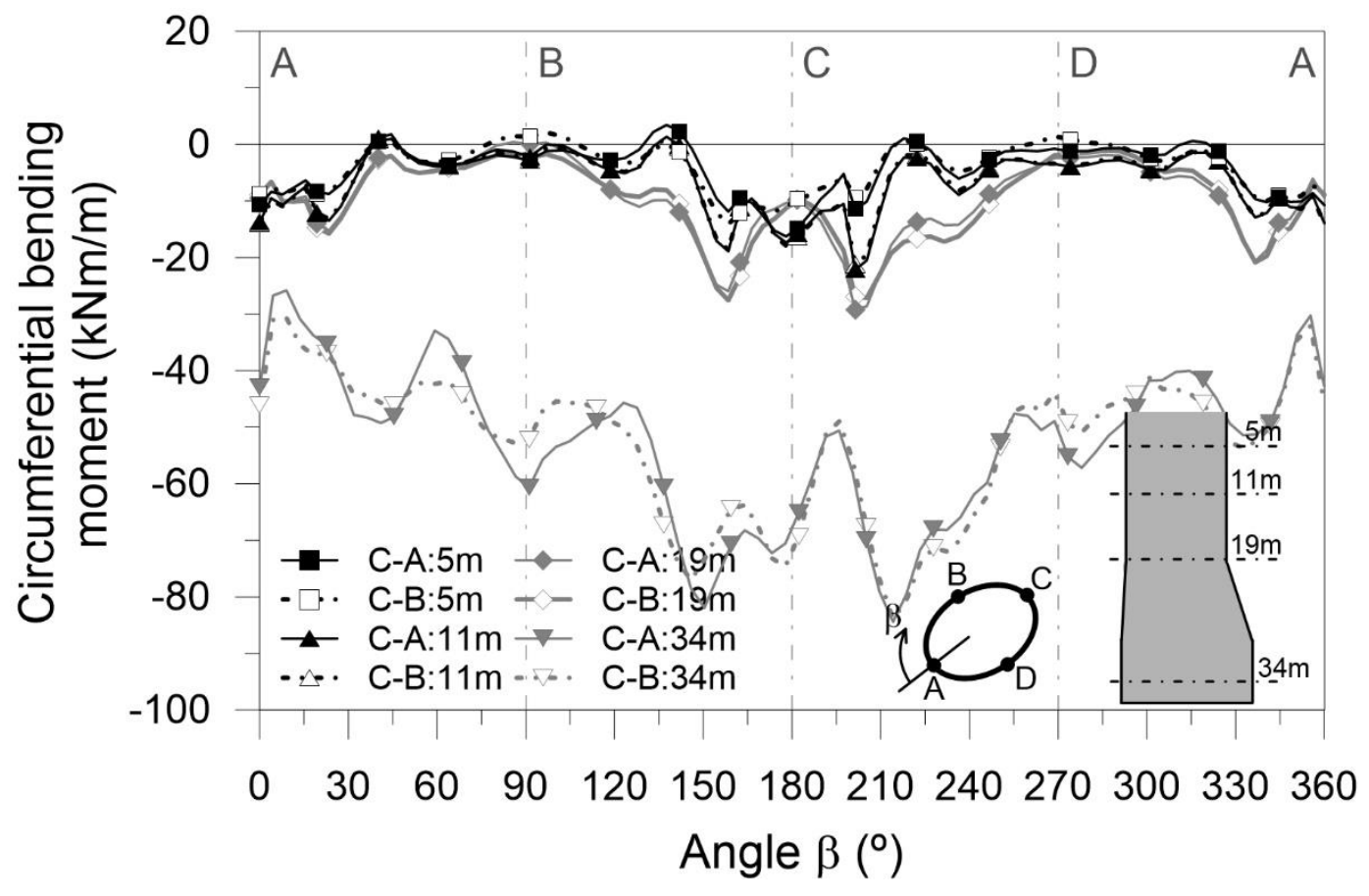


413 The profiles of the normal total pressure on the outside of the shaft, at the end of shaft construction, are shown in Figure 20 from both analyses and at the 4 principal alignments, paired across the major $(A, C)$ and minor $(B, D)$ axes respectively. Also shown in the figure are profiles of the horizontal total stress at the beginning of the analyses ("Greenfield" - increment 0 in Table 3) and at the beginning of the shaft construction ("Initial" - increment 50 in Table 3). Comparison of these profiles reveals that the construction of the buildings and of the Baixa-Chiado station induced some modifications to the horizontal total stresses at the shaft location, with a noticeable reduction of stress in the limestone layer and a slight increase at depth on the side closest to the station (alignment C). At the end of shaft construction the profiles from the two analyses are almost identical throughout the depth of the shaft. At alignments $\mathrm{A}$ and $\mathrm{C}$ (major axis) a slight increase of stress is predicted in the $A E$ layer above the limestone, while stress concentration is predicted in the upper part of the limestone layer. In the $A E$ layer immediately below the limestone and down to the ground water table $(23 \mathrm{~m})$ there are no significant stress changes compared to initial profiles. However, at depths below the water table, from the mid-transition zone to the base, a considerable stress reduction occurs in all remaining layers, with a concentrated stress increase only in the TAP layer. In contrast, at alignments B and D on the minor axis, the normal pressure at the end of shaft construction is much reduced almost to the start of the circular section, broadly following the greenfield and initial profiles thereafter, with an exception again of a concentrated stress increase in the TAP layer. These results are in agreement with the deformational mechanisms usually observed in this type of section. In the elliptical section the stresses tend to increase along the major axis and decompress the soil along the minor axis due to an arching effect. Naturally, this behaviour is associated with the predicted displacements (see Figure 13 and 14), which are higher along the minor axis and nearly zero along the major axis. The behaviour in the 

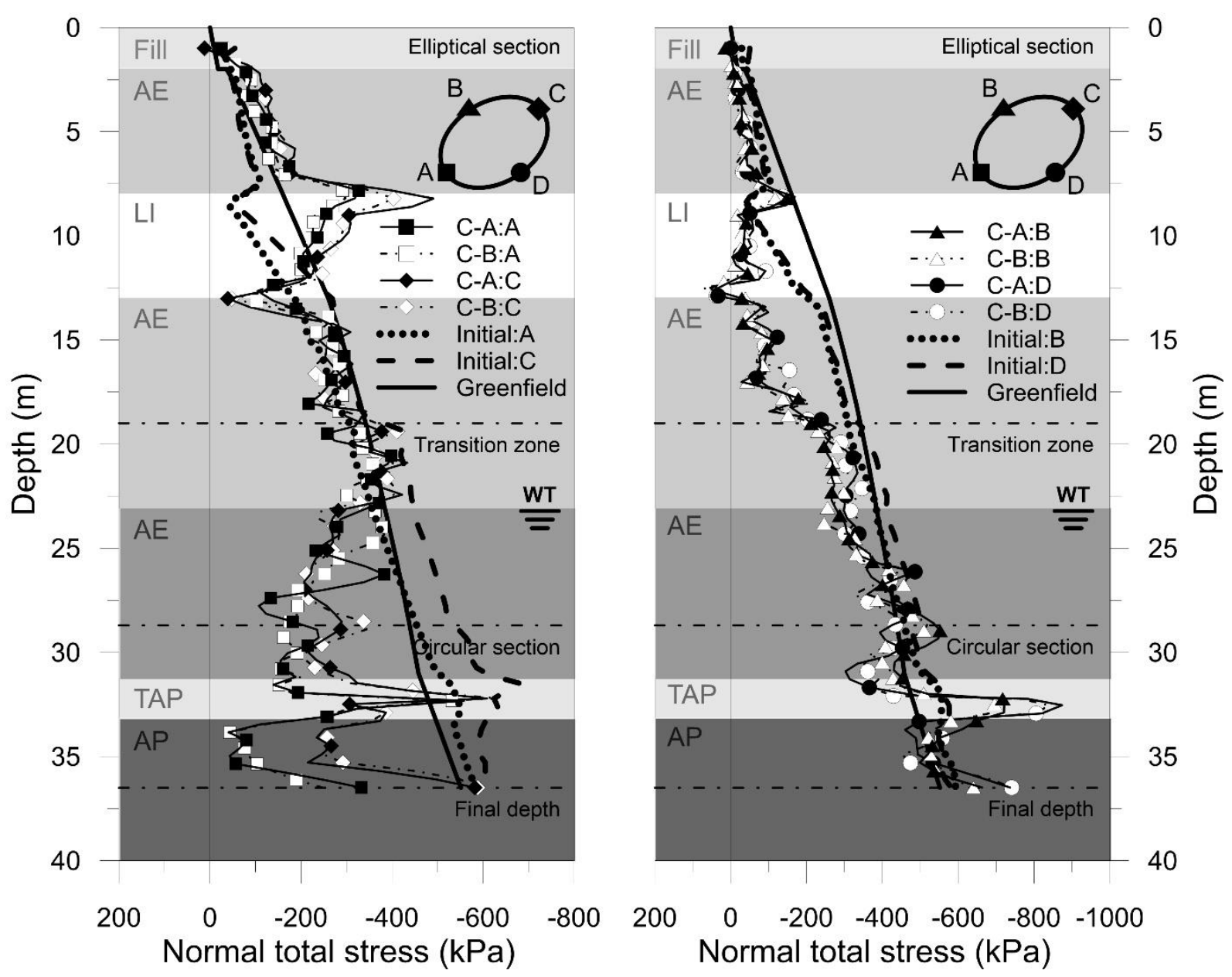

Figure 20 - Normal total pressure on the shaft in the principal alignments A, B, C, D

\subsection{INFLUENCE OF THE EXCAVATION ON THE BAIXA-CHIADO STATION}

\section{Displacements in the station lining}

Figure 21 shows contours of the vertical displacements predicted in the West gallery for different

construction stages of the shaft. As noted above, at the depth of the station the influence of the

stiffness of the buildings is marginal, consequently only the results of Analysis C-A are presented. The

influence of the construction of the Ivens shaft on the Baixa-Chiado station starts to be noticeable at

an excavation depth of $25 \mathrm{~m}$. From this depth onwards the vertical displacements rise steadily, 
of shaft excavation on the station, with a $2 \mathrm{~mm}$ maximum movement towards the shaft. The most affected area is around the connection tunnel. The longitudinal ( $Z$ direction) of the station is practically unaffected by shaft excavation, with movements less than $0.5 \mathrm{~mm}$.

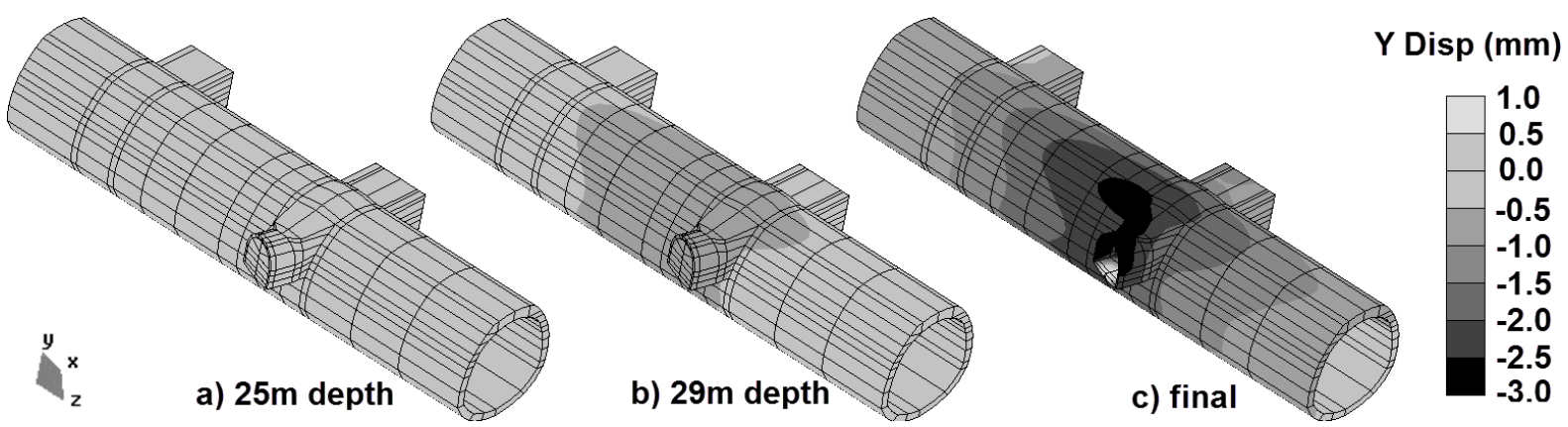

Figure 21 - Evolution of the vertical displacements in the West gallery of the Baixa-Chiado station

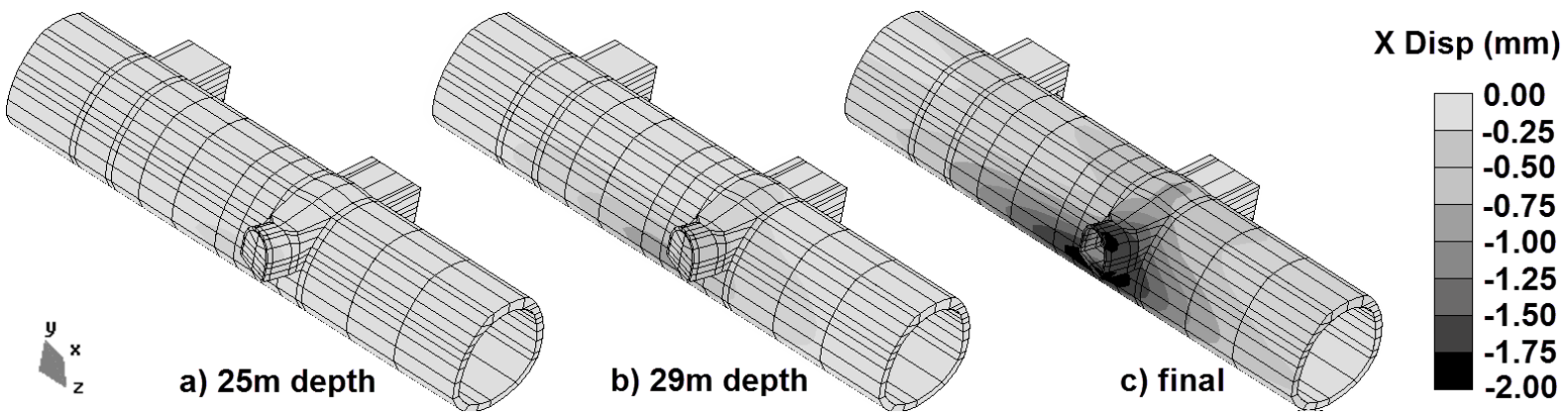

Figure 22 - Evolution of the horizontal displacements ( $\mathrm{X}$ direction) in the West gallery of the Baixa-Chiado station

\section{Forces acting in the station lining}

The changes in the circumferential bending moment and hoop force in the lining of the Baixa-Chiado station, induced by shaft and connection tunnel construction, are plotted in Figure 23 for 5 transverse cross sections in the West gallery. These sections are denoted with reference to their distance from the centreline of the connection tunnel $(0 \mathrm{~m})$. As expected, the impact of shaft construction is higher in the sections located in the vicinity of the shaft $( \pm 9 \mathrm{~m})$, with maximum changes, in absolute terms, reaching $300 \mathrm{kNm} / \mathrm{m}$ and $500 \mathrm{kN} / \mathrm{m}$ for bending moment and hoop force respectively, or $30 \%$ and $15 \%$ respectively with respect to the values before shaft construction. The effect reduces with distance, becoming negligible, in terms of the percentage difference, after about $\pm 45 \mathrm{~m}$, or 3 diameters of the shaft's circular section. In general, a decrease in structural forces is predicted at the tunnel crown and invert (angle $\beta$ at around $0^{\circ}$ and $180^{\circ}$ ), while an increase of forces is predicted at the spring lines $(\beta$ 
at around $90^{\circ}$ and $270^{\circ}$ ). These variations are in agreement with the deformation mechanism observed in the station (Figure 21 and 22), as the lateral decompression of the soil causes the lining to squat, hence increasing the forces at the spring lines and decreasing them at the crown and invert.
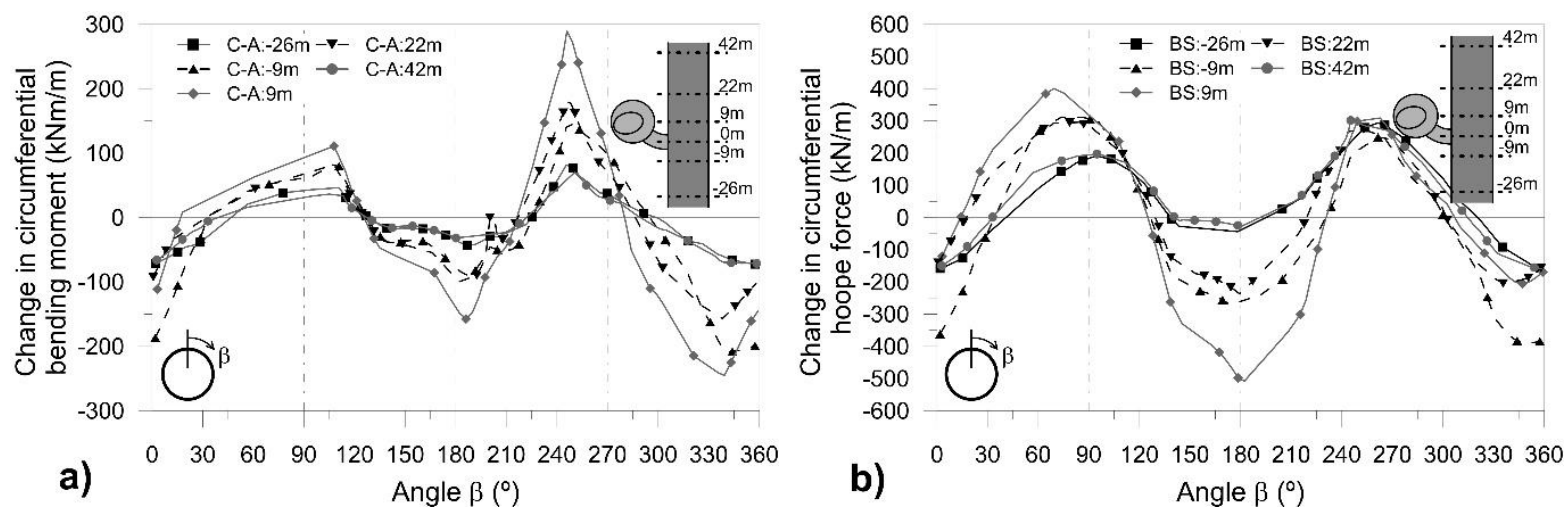

Figure 23 - Changes of the structural forces mobilised in the West tunnel of the Baixa-Chiado station for the final stage of construction: a) circumferential bending moments; b) circumferential hoop force

\subsection{INFLUENCE OF THE EXCAVATION ON THE BUILDINGS}

As demonstrated earlier, the influence of the stiffness of the buildings has a significant impact on the displacements at ground surface. In Analysis C-A (no building stiffness) concentric displacement contours are predicted around the shaft, while in Analysis C-B the spatial distribution and magnitude of these deformations is modified and restrained by the presence of the buildings (see Figure 11). These distributions imply significant differences in the settlement troughs and in the horizontal strains at a buildings' foundation level, which in turn influence the potential damage to the buildings. A simple risk assessment of the Quintão building, based solely on the evaluation of the tilt $(\omega)$, relative rotation $(\beta)$, deflection ratio $\left(\Delta_{\max } / L\right)$ and horizontal strain $\left(\varepsilon_{h}\right)$, defined according to Burland \& Wroth (1974), is performed for both analyses. The results are summarised in Table 4, from which it is clear that the analysis C-A indicates the most detrimental values for all parameters of risk and these values imply slight damage to the Quintão building (Category 1, according to Boscardin \& Cording (1989); Burland (1995)). In contrast, analysis C-B indicates no building damage (Category 0). 


\begin{tabular}{ccccccccc}
\hline Building & $\mathbf{L}(\mathbf{m})$ & $\mathbf{H}(\mathbf{m})$ & Analysis & $\omega$ & $\beta$ & $\Delta_{\max }(\mathbf{m m})$ & $\Delta_{\max } / \mathrm{L}(\%)$ & $\varepsilon_{\mathrm{h}}(\%)$ \\
\hline \multirow{2}{*}{ Quintão } & \multirow{2}{*}{17.0} & \multirow{2}{*}{15.0} & $\mathrm{C}-\mathrm{A}$ & $1 / 1039$ & $1 / 357$ & 8.42 & 0.056 & 0.030 \\
& & & $\mathrm{C}-\mathrm{B}$ & $1 / 1563$ & $1 / 3306$ & 1.46 & 0.010 & 0.002 \\
\hline
\end{tabular}

489

490

491

492

493

494

495

496

497

498

499

500

501

502

503

504

505

506

507

508

509

510

511

512

513

\section{CONCLUSIONS}

The main objective of this paper was to assess the soil-structure interaction of a complex deep excavation surrounded by several surface structures and next to an existing metro station, using advanced 3D FE analyses in conjunction with carefully characterised soils in the ground profile around this excavation. Although the study applies to specific ground conditions characteristic of the city of Lisbon in Portugal and presents class A predictions (i.e. before field construction) for the Ivens shaft excavation in these ground conditions, it demonstrates several aspects of interaction between new construction and existing structures and services that are important to consider for a realistic numerical analysis of the boundary value problem.

- Simulation of site history, in this case of the presence of the buildings and of the Baixa-Chiado station, prior to shaft construction, is required for establishing realistic current ground conditions at the site, which were shown to be significantly altered compared to a simple greenfield assumption.

- Accounting for building stiffness is essential for reproducing realistically its effect on ground movements induced by underground construction. Shallow founded buildings in the current study have a significant impact on the deformations at the ground surface, modifying both the pattern and the magnitude of displacements by up to $40 \%$.

- The effect of the shallow-founded buildings on movements is limited to the superficial soil layers.

- The settlements of the shaft lining, as a result of the adopted specific construction sequence, are predicted to increase almost linearly with depth, while the significant convergence in terms of horizontal movements is predicted across its minor axis throughout its entire depth. The net horizontal movement across the major axis is almost negligible.

- The adopted shaft construction sequence results in small circumferential bending moments in the lining, but significant circumferential hoop forces which increase with depth. 
- The earth pressures normal to the lining are significantly altered by the shaft construction compared to the profiles at the start of shaft excavation. The pressures have reduced in the lower half of the shaft across the shaft's major axis, while the same is true for the upper half of the shaft across its minor axis.

- The effects of shaft construction on the West tunnel of the Baixa-Chiado station is felt only when the excavation of the shaft reaches the depth of the tunnel crown. This effect is localised around the connection tunnel (between the shaft and the West station tunnel) and diminishes within a distance of 2 to 3 shaft diameters from the connection tunnel. It is manifested in up to $30 \%$ change in structural forces in the lining of the West station tunnel.

- The results also demonstrate that the manner in which the buildings are represented in the current analysis enables a simple risk assessment for building damage to be conducted

\section{ACKNOWLEDGMENTS}

The authors wish to acknowledge the support provided by FCT - Fundação para a Ciência e Tecnologia, Portugal (grant reference SFRH / BD / 43845 / 2008), the Lisbon Metro and the TPF Planege Cenor (former Cenorgeo), for the PhD research of the first author, conducted at Imperial College London, UK, and the University of Coimbra, Portugal. 


$a_{0} ; a_{1} ; a_{2} /$
$r_{0} ; r_{1} ; r_{2}$
$A_{\text {slab }}$
$b / s$
$\beta$
$c^{\prime}$
$\Delta \phi^{\prime}$
$\Delta_{\max }$
$\varepsilon_{h}$
$E$
$E_{d}$

$(E A)_{\text {building }}$

$(E I)_{\text {building }}$

$E_{\text {equiv }}$

$E_{\text {slab }}$

$\theta$

$G_{\max }$

$G_{\text {tan }}$

$\gamma$

$G_{0} / K_{0}$

$h_{m}$

$H_{\text {equiv }}$

$I_{\text {slab }}$

PI

J

k

$K_{0}$

$K_{\max }$

$K_{\text {tan }}$

L

$m_{G} / m_{K}$

$m$

$v$

$p^{\prime}$
Constants affecting the degradation of shear and bulk moduli

Area of the slab

Constant affecting the degradation of shear and bulk moduli

Relative rotation of the building

Cohesion

Amplitude of the variation of the angle of shear resistance

Maximum deflection of the building

Horizontal strain

Young's modulus

Generalised deviatoric strain

Axial stiffness of the structure

Bending stiffness of the structure

Equivalent Young's modulus of the building

Effective Young's modulus of the slab

Lode's angle - third invariant of the stress tensor

Maximum tangent shear modulus

Tangent shear modulus

Unit weight

Constant affecting the maximum shear and bulk moduli

Distance to the neutral axis of the structure

Equivalent height of the building

Inertia of the slab

Plastic Index

Deviatoric stress - second invariant of the stress tensor

Permeability

Earth pressure coefficient at rest;

Maximum tangent bulk modulus

Tangent bulk modulus

Length of the building

Stress level dependency parameter in the shear and bulk moduli

Number of storeys

Poisson's ratio

Mean effective stress 


$p_{N}^{\prime}$
$p^{\prime}{ }_{r e f}$
$R_{G, \min } / R_{K, \min }$
$\phi^{\prime}$
$\phi^{\prime}{ }_{b}$
$\psi$
$\omega$

533

534
Mean effective stress at the average secant angle of shearing resistance Reference pressure

Constant affecting the degradation of shear and bulk moduli Angle of shear resistance

Basic angle of shear resistance

Dilatancy

Tilt of the building 
Anagnostopoulos, C. \& Georgiadis, K. (2002) Behaviour of an instrumented circular diaphragm wall. In Proceedings of the 15th international conference on soil mechanics and geotechnical engineering, Istambul. AA Balkema publishers, Vol. 2, pp. 1061-1064.

Andrade, J. C., Campanhã, C. A., Almeida, C. A., Mota, A. \& Jordão, P. (2004) Underground stations in shafts and tunnels at the Oporto subway. General design aspects and construction technical support. In Proceedings of the IX - National Conference in Geotechnics, Averio, Portugal. Vol. III, pp. 255-264 (in Portuguese).

Arai, Y., Kusakabe, O., Murata, O. \& Konishi, S. (2008) A numerical study on ground displacement and stress during and after the installation of deep circular diaphragm walls and soil excavation. Computers and Geotechnics, 35 (5), pp. 791-807. (in English).

Barros, J., Iyomasa, W., Azevedo, A., Eisenstein, Z. \& Assis, A. (2008) Lessons from Brazil: Pinheiros examined. Tunnels \& Tunnelling international, (Nov), pp. 16-21.

Boscardin, M. D. \& Cording, E. J. (1989) Building response to excavation induced settlement. Journal of Geotechnical Engineering-Asce, 115 (1), pp. 1-21.

Burland, J. B. \& Wroth, C. P. (1974) Settlement of buildings and associated damage. In Proceedings of the Conference 'Settlement of structures', Cambridge. Pentech, London, pp. 611-654.

Burland, J. B. (1995) Assessment of risk of damage to buildings due to tunnelling and excavation. In Proceedings of the 1st International conference on earthquake geotechnical engineering, IS Tokyo '95. Ishihara, K. (ed.), Vol. 3, pp. 1189-1201.

Cabarkapa, Z., Milligan, G. W. E., Menkiti, C. O., Murphy, J. \& Potts, D. M. (2003) "Design and performance of a large diameter shaft in Dublin Boulder Clay" BGA International Conference on Foundations: Innovations, observations, design and practice, pp. 175-185.

Campanhã, C. A. \& Kuwajima, F. M. (2008) Designing concepts of large shafts and tunnel stations using NATM. In Proceedings of the 2nd Brazilian conference of tunnels and underground structures, (in Portuguese).

Candeias, M. A. S., Brito, J. A. M., Matos Fernandes, M. \& Lopes, P. G. (2007) Jet-grouting solution to link a tunnel to a cut-and-cover excavation. Ground Improvement, 11 (1), pp. 3-10.

Cenorgeo (2008) Design project of Ivens Shaft - Baixa-Chiado metro station of the Lisbon Metro. Cenorgeo. pp. 350 (in Portuguese).

França, P., Taborda, D. M. G., Pedro, A. M. G., Almeida e Sousa, J. \& Topa gomes, A. (2006) Salgueiros station of the Oporto Metro - analysis of its behaviour. In Proceedings of the XIII COBRAMSEG / III CLBG / IV SBMR, Curitiba, Brazil. pp. 6 (in Portuguese).

Franzius, J. N. (2003) Behaviour of buildings due to tunnel induced subsidence. PhD thesis. Imperial College of London, London.

Franzius, J. N., Potts, D. M. \& Burland, J. B. (2006) The response of surface structures to tunnel construction. Proceedings of the Institution of Civil Engineers-Geotechnical Engineering, 159 (1), pp. 3-17.

Goto, S., Muramatsu, M. \& Sueoka, T. (1994) Ground movement, earth and water pressures due to shaft excavations. In Proceedings of the International Symposium on Underground Construction in Soft Ground, New delhi, India. Saka, F., Yabe, H., Watanabe, H., Shimbo, K., Fujita, K. \& Kusakabe, O. (eds.), pp. 151-154.

Holl, G. W. \& Fairon, E. G. (1973) A review of some aspects of shaft design. Journal of the South African Institute of Mining and Metallurgy, 73 pp. 309-324.

IPT (2008) Relatório sobre o Acidente da Estação Pinheiros. Instituto de Pesquisas Tecnológicas. (in Portuguese).

Kumagai, T., Ariizumi, K. \& Kashiwagi, A. (1999) Behaviour and analysis of a large-scale cylindrical earth retaining structure. Soils and Foundations, 39 (3), pp. 13-26.

Lambe, T. W. (1973) Predictions in soil engineering. Geotechnique, 23 (2), pp. 149-202. 
McNamara, A., Roberts, T., Morrison, P. \& Holmes, G. (2008) Construction of a deep shaft for Crossrail. Proceedings of the Institution of Civil Engineers-Geotechnical Engineering, 161 (6), pp. 299-309.

Morrison, P. R. J., McNamara, A. M. \& Roberts, T. O. L. (2004) Design and construction of a deep shaft for Crossrail. Proceedings of the Institution of Civil Engineers-Geotechnical Engineering, 157 (4), pp. 173-182.

Muramatsu, M. \& Abe, Y. (1996) Considerations in shaft excavation and peripheral ground deformation. In Proceedings of the Geotechnical Aspects of Underground Construction in Soft Ground Mair, R. J. \& Taylor, R. N. (eds.), pp. 173-178.

Panet, M. \& Guenot, A. (1982) Analysis of convergence behind the face of a tunnel. In Proceedings of the Conference Tunnelling '82, London, UK. Institute of Mining and Metallurgy, London, pp. 197-204.

Pedro, A. M. G. (2013) Geotechnical investigation of Ivens shaft in Lisbon. PhD Thesis. Imperial College London, London, UK.

Pedro, A. M. G., Zdravković, L., Potts, D. \& Almeida e Sousa, J. (2017) Derivation of model parameters for numerical analysis of the Ivens shaft excavation. Engineering Geology, 217 pp. 49-60.

Pedro, A. M. G., Zdravković, L., Potts, D. \& Almeida e Sousa, J. (2018) Geotechnical characterization of the Miocene formations at the location of Ivens shaft, Lisbon. Quarterly Journal of Engineering Geology and Hydrogeology, 51 (1), pp. 96-107.

Postiglione, P., Abrantes, J. R. d. C., Pinto, F. A. D., Mosiici, P. \& Altan, V. D. (1997) Consolidations by jet grouting previous to escavations of the western station of the "Baixa-Chiado" twin stations of the Lisbon Metro. In Proceedings of the VI National Conference in Geotechnics, Lisbon. pp. 1125-1134 (in Portuguese).

Potts, D. M. \& Zdravković, L. (1999) Finite element analysis in geotechnical engineering: theory. Thomas Telford. London.

Potts, D. M. \& Zdravković, L. (2001) Finite element analysis in geotechnical engineering: application. Thomas Telford. London.

Rabcewicz, L. (1964) The New Austrian Tunnelling Method. Water Power, 16 (11), pp. 453-457.

Schwamb, T. \& Soga, K. (2015) Numerical modelling of a deep circular excavation at Abbey Mills in London. Géotechnique, 65 (7), pp. 604-619.

Standing, J., Farina, M. \& Potts, D. (1998) "The prediction of tunnelling induced building settlements-a case study", Balkema, Rotterdam, pp. 1053-1058.

Taborda, D. M. G., Potts, D. M. \& Zdravković, L. (2016) On the assessment of energy dissipated through hysteresis in finite element analysis. Computers and Geotechnics, 71 pp. 180-194.

Tavares, G. N. S., Silva, L. M. M., Baião, C., Mateus de Brito, J., Almeida e Sousa, J. \& Pedro, A. M. G. (2010) Design of the Trofa railway tunnel - Portugal. In Proceedings of the XII National Conference in Geotechnics, Guimarães, Portugal. pp. 10 (in Portuguese).

Topa Gomes, A. (2008) Elliptical shafts open by the sequential excavation method-Oporto Metro. PhD thesis. University of Porto, Porto (in Portuguese).

Topa Gomes, A., Silva Cardoso, A., Almeida e Sousa, J., Andrade, J. C. \& Campanhã, C. A. (2008) Design and behavior of Salgueiros station for Porto metro. In Proceedings of the International Conference on Case Histories in Geotechnical Engineering, Missouri University of Science and Technology, USA.

Viggiani, G. \& Standing, J. (2001) "26 The Treasury" Building response to tunnelling: case studies from construction of the Jubilee Line Extension, London, Thomas Telford Publishing, pp. 401-432.

Vincenza, F., Enrico, F., Giordano, R. \& Astore, G. (2012) Three case-histories deal with design and construction of large shafts. In Proceedings of the 3rd Int. Conf. On Shaft Design and Construction, London, UK. IOM3, pp. 10.

Zdravkovic, L., Potts, D. M. \& John, H. D. S. (2005) Modelling of a 3D excavation in finite element analysis. Géotechnique, 55 (7), pp. 497-513. 


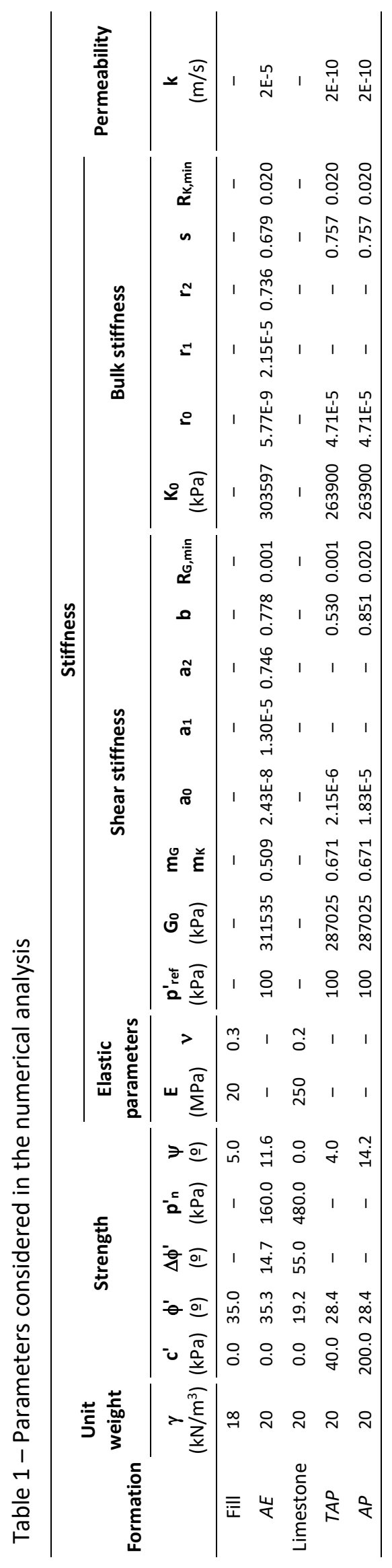


637 NONLINEAR MOHR-COULOMB FAILURE CRITERION

$$
\begin{aligned}
& F=\frac{J}{\left(\frac{c^{\prime}}{\tan \phi^{\prime}}-p^{\prime}\right) \cdot g(\theta)} \\
& g(\theta)=\frac{\sin \phi^{\prime}}{\cos \theta-\frac{\sin \theta \cdot \sin \phi^{\prime}}{\sqrt{3}}} \\
& \phi^{\prime}=\phi^{\prime}{ }_{b}+\frac{\Delta \phi^{\prime}}{1+\frac{p^{\prime}}{p^{\prime}}}
\end{aligned}
$$

638 IMPERIAL COLLEGE GENERALISED SMALL STRAIN STIFFNESS MODEL

$$
\begin{aligned}
& G_{\text {max }}=G_{0} \cdot\left(\frac{p^{\prime}}{p_{\text {ref }}^{\prime}}\right)^{m_{G}} \\
& K_{\text {max }}=K_{0} \cdot\left(\frac{p^{\prime}}{p_{\text {ref }}^{\prime}}\right)^{m_{K}} \\
& G_{\text {tan }}=G_{\text {max }} \cdot\left(R_{G, \text { min }}+\frac{\left(1-R_{G, \text { min }}\right)}{1+\left(\frac{E_{d}}{a}\right)^{b}}\right) \\
& K_{\text {tan }}=K_{\text {max }} \cdot\left(R_{K, \text { min }}+\frac{\left(1-R_{K, \text { min }}\right)}{1+\left(\frac{E_{d}}{r}\right)^{s}}\right) \\
& a=a_{0}+a_{1} \cdot\left(\frac{p^{\prime}}{p_{\text {ref }}^{\prime}}\right)^{a_{2}} \\
& r=r_{0}+r_{1} \cdot\left(\frac{p^{\prime}}{p_{\text {ref }}^{\prime}}\right)^{r_{2}}
\end{aligned}
$$

639 DETERMINATION OF THE STIFFNESS OF THE BUILDINGS

$$
\begin{aligned}
& (E I)_{\text {building }}=E_{\text {slab }} \cdot \sum_{i}^{m+1}\left(I_{\text {slab }}+A_{\text {slab }} \cdot h_{m}^{2}\right) \\
& (E A)_{\text {building }}=E_{\text {slab }} \cdot A_{\text {slab }} \cdot(m+1) \\
& H_{\text {equiv }}=\sqrt{\frac{12 \cdot(E I)_{\text {building }}}{(E A)_{\text {building }}}} \\
& E_{\text {equiv }}=\frac{(E A)_{\text {building }}}{H_{\text {equiv }}}
\end{aligned}
$$

